\title{
E-shape Metamaterials Embedded Implantable Antenna for ISM-band Biomedical Applications
}

Amaria Saidi ( $\nabla$ saidii.amaria@gmail.com )

Universite Dr Tahar Moulay de Saida

Keltouma Nouri

Universite Dr Tahar Moulay de Saida

Boubakar Seddik Bouazza

Universite Dr Tahar Moulay de Saida

Kada Becharef

Universite Dr Tahar Moulay de Saida

Abdelhamid Cherifi

Universite Dr Tahar Moulay de Saida

Turkiya Abes

Universite Dr Tahar Moulay de Saida

\section{Research Article}

Keywords: Antenna, design, metamaterial, E-shape resonator, ISM bands, Miniature

Posted Date: April 26th, 2021

DOI: https://doi.org/10.21203/rs.3.rs-294989/v1

License: (c) (i) This work is licensed under a Creative Commons Attribution 4.0 International License. Read Full License

Version of Record: A version of this preprint was published at Research on Biomedical Engineering on January 22nd, 2022. See the published version at https://doi.org/10.1007/s42600-021-00191-y. 


\title{
E-shape Metamaterials Embedded Implantable Antenna for ISM-band Biomedical Applications
}

\author{
SAIDI Amaria*, NOURI Keltouma*, BOUAZZA Boubakar Seddik*, BECHAREF Kada*, CHERIFI \\ Abdelhamid*, ABES Turkiya* \\ * LTC Laboratory, Faculty of Technology, Department of Electronics \\ University of Saida Dr. Moulay Tahar, Algeria \\ E-mail: nouri.keltouma@univ-saida.dz, saidii.amaria@gmail.com
}

\begin{abstract}
This paper presents a compact antenna based on two different metamaterial resonators, the E-shape resonators and the interdigital resonators suitable for biomedical implant applications. The proposed antennas operate in the industrial, scientific, and medical (ISM) bands in the frequency band of 2.42.5 GHz. The integration of metamaterial (MTM) in the design leading to the reduce size of these antennas and gaining enhancement. The overall size of the proposed antennas is $8 \times 7 \times 1.27 \mathrm{~mm}^{3}$. The implantable antennas contain two layers of the substrate; the lower layer comprises the MTM resonators and the upper, superstrate layer. To order to observe the exposure of electromagnetic energy to human tissues, the specific absorption rates (SARs) of the proposed antennas are also calculated in the layer model. The antennas are designed and simulated by the two software simulators CST and HFSS.
\end{abstract}

Index Terms - Antenna, design, metamaterial, E-shape resonator, ISM bands, Miniature.

\section{INTRODUCTION}

The implantable medical devices (IMDs) play an important role in telemetry. They allow the transmission of information from inside the human body to the base station Fig.1 [1]. The antenna is the important element in IMDs which is responsible for the transmission of this information between the IMDs and the external equipment [2]. The antenna design has become one of the most active areas of the communications studies and must be adapted to meet the requirements of the new applications [3], [4].

The design of the implantable antenna must meet some essential requirements such as compact size, biocompatibility, patient safety, flexibility, and the low value of specific absorption rate (SAR) [5]. One of the key challenges is the miniaturization of the patch antenna. A variety of techniques have been proposed like a high dielectric constant material [6], loading shorting pins to connect the patch and the ground [7], metamaterial split ring resonator (SRR)[8].
The design steps needed to design implantable antennas are described in [9]. The implantable antenna is used in the medical implant communication service (MICS) band which is between $402-405 \mathrm{MHz}$ and in the industrial, scientific, and medical (ISM) bands $(433.1-434.8 \mathrm{MHz}, 868-868.6 \mathrm{MHz}$, 902.8-928MHz and 2400-2500MHz) [10].

Metamaterials (MTMs) are engineered materials with extraordinary property not usually found in nature such as the negative permittivity $\varepsilon$, permeability $\mu$, and the refractive index $n$ [11-12]. The theoretically properties of this material were first introduced by the Russian scientist Victor Veselago [13]. Researchers are interested in metamaterials and their follow-up in many fields, especially in the microwave field [14-15]. There are several forms of metamaterials were introduced, such as split ring resonators SRR circular and square [16], the complementary SRRs [17], S-shape [18] and G-shape [19]...

The use of metamaterials in the design of implantable antennas has become interesting, sitting some work, MTMloaded CP implantable antenna [20], a compact SRR based antenna [21], a metamaterial-inspired CP antenna for implantable application [22].

In this paper, two metamaterials resonators embedded antenna are proposed, E-shape resonators and E-interdigital, for use in multiple bio-telemetry applications in the upper-frequency band of ISM 2.4-2.5 GHz. Adding the two proposed resonators are designed on the substrate layer of the proposed antenna and simulated in different human layers tissues such as the skin, fat, and muscle.

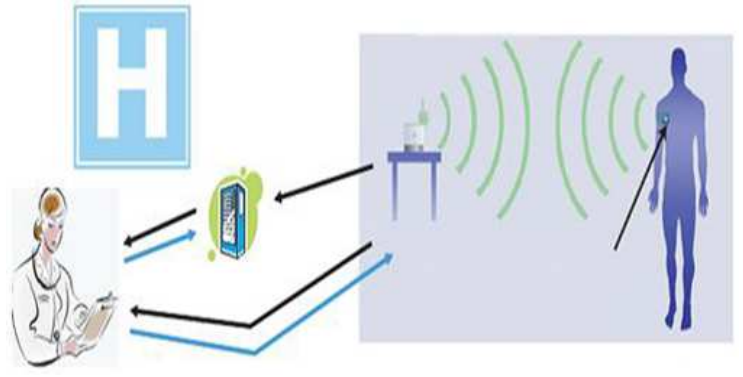

Fig.1. Illustration of a health monitoring system [1]. 


\section{ANTENNA WITH FOUR E-SHAPE RESONATORS}

\section{A. Antenna Design Specifications}

The proposed two bonded E-shape MTM resonator loaded by four E-shapes is shown in Fig.2. The overall size of the proposed antenna is $8 \times 7 \times 1.27 \mathrm{~mm}^{3}$. The antenna contains a radiation patch, full ground, and two layers of substrate, the first layer consisting of patch radiation and the four MTM Eshape resonators and the second, superstrate layer. The designed antenna is standardized to $50 \mathrm{ohms}$ and is fed by a coaxial cable and shorting pin with $0.15 \mathrm{~mm}$ and $0.1 \mathrm{~mm}$ diameter, respectively. A RO3010 with a dielectric permittivity constant $\left(\varepsilon_{r}=10.2\right)$ and the loss tangent $(\tan \delta=0.0035)$ and $0.635 \mathrm{~mm}$ thickness is used as substrate and superstrate layer. The proposed antenna operates on a $2.45 \mathrm{GHz}$ resonance frequency.

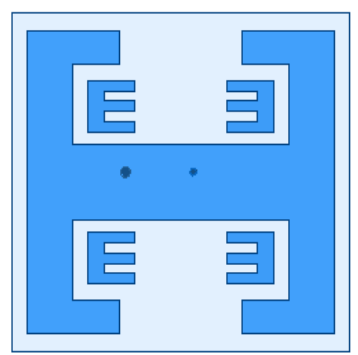

(a)

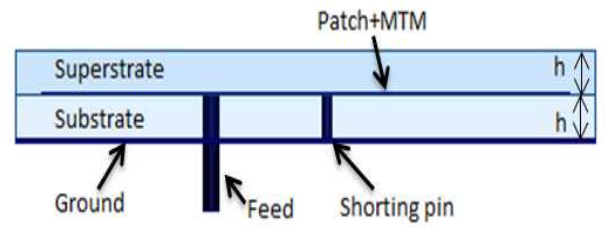

(b)

Fig.2. The proposed antenna (a) Two bonded E loaded by MTM four Eshape resonators (b) Side view.

\section{B. Metamaterial unit cell}

In this work, the design of the MTM resonator is formed by the E-shape resonator as shown in Fig.3. This structure is treated by High Frequency Structure Simulator (HFSS) software. The perfect electric conductor (PEC) boundary is applied along the $\mathrm{Y}$-axis and the perfect magnetic conductor (PMC) boundaries are applied along the $\mathrm{X}$-axis. Electromagnetic waves pass through port 1 and port 2, which are perpendicular to the boundaries PEC and PMC, along the Z-axis, as shown in Fig.3-(b). The values parameters of the Eshape resonator are $e=d=1.5 \mathrm{~mm}$ and $\mathrm{g}=0.3 \mathrm{~mm}$.

To check the presence of metamaterial in the proposed Eshape, the Nicolson Ross Weir (NRW) method is used to extract the effective parameters of the MTM: permeability, permittivity and refractive index [23]. This method uses the following equations:

$V_{1}=S_{21}+S_{11}$

$V_{2}=S_{21}-S_{11}$ $\mu_{\text {eff }}=\frac{2}{\left(j K_{0} d\right)} \frac{\left(1-V_{2}\right)}{\left(1+V_{2}\right)}$

$\varepsilon_{e f f}=\frac{2}{\left(j K_{0} d\right)} \frac{\left(1-V_{1}\right)}{\left(1+V_{1}\right)}$

$n_{e f f}=\sqrt{u_{e f f} \times \varepsilon_{e f f}}$

Where:

$\mathrm{K}_{0}$ is wave number in free space $\left(\mathrm{K}_{0}=\frac{\omega}{\mathrm{C}}\right), \omega$ is the angular frequency and $\mathrm{c}$ is the speed of light in free space, $\mathrm{C}=3 \times 108$ $\mathrm{m} / \mathrm{s}$.

d: The thickness of the substrate.

$\mathrm{S}_{11}, \mathrm{~S}_{21}$ : The S-parameters.

$\varepsilon_{\text {eff }}$ and $\mu_{\text {eff }}$ are the effective permittivity and effective permeability.

$n_{\text {eff }}$ is the refractive index

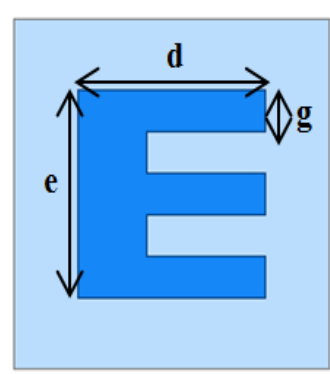

(a)

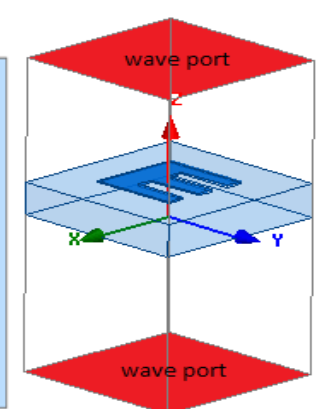

(b)
Fig.3. (a) The cross sectional view of MTM E-shape resonator, (b) Unit cell.

Figure 4 illustrates the reflection coefficient $S_{11}$ and the transmission coefficient $S_{21}$ of the proposed E shape resonator concerning frequency.

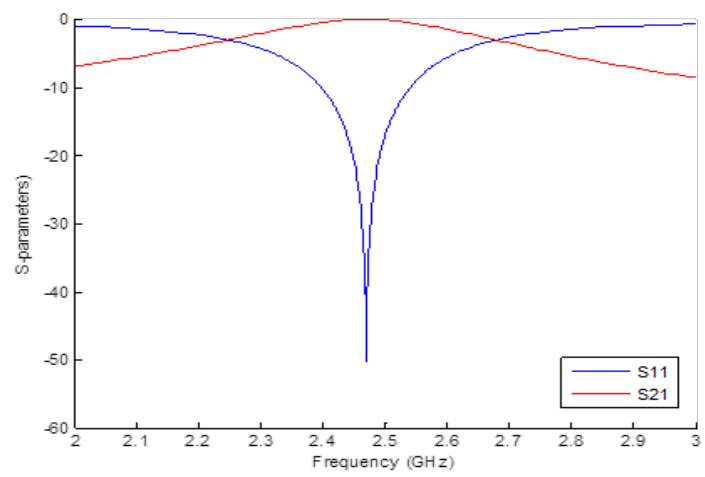

Fig.4. S-parameters $\left(\mathrm{S}_{11}, \mathrm{~S}_{21}\right)$.

From the S-parameters, we extracted the values of permittivity, permeability, and refractive index, as shown in fig.5. 


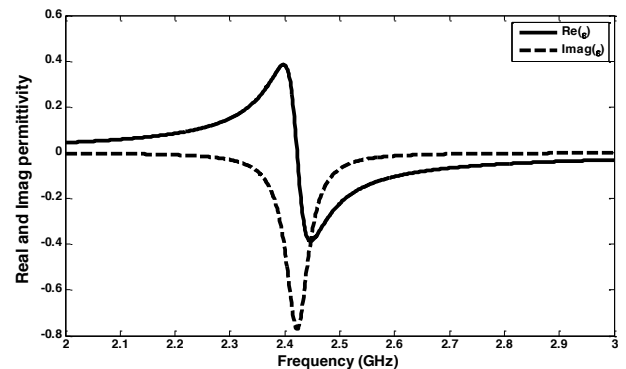

(a)

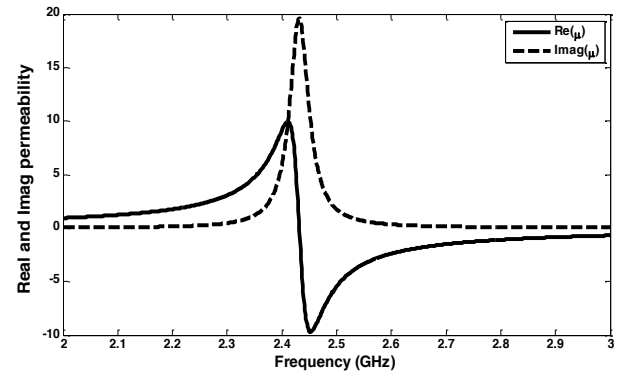

(b)

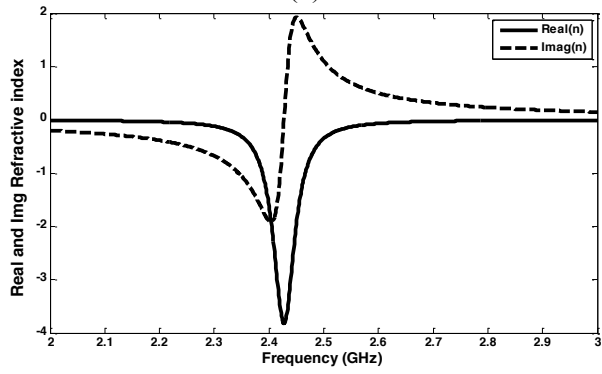

(C)

Fig.5. the real and imaginary part of (a) Permittivity (b) Permeability and (c) Refractive index.

\section{C.Design and simulation environments of MTM planar antennas based on E- shaped unit cells}

The proposed two bonded E loaded by four MTM E-shape resonators modeled and analyzed in HFSS and CST (computer Simulation Technology). Firstly, the proposed antenna is operated in free space by two steps. In the first step, the antenna simulated with tow bonded E like shown in Fig.6.a with the values parameters: $\mathrm{Wg}=12 \mathrm{~mm}, \mathrm{Lg}=11 \mathrm{~mm}$, $\mathrm{Wp}=10.4 \mathrm{~mm}, \mathrm{Lp}=9.4 \mathrm{~mm}$, and $\mathrm{d}=7.4 \mathrm{~mm}$. In the second step, the antenna is simulated by adding the four MTM E-shape resonators which allows us to optimize the values parameters to obtain the desired frequency, Fig.6.b.

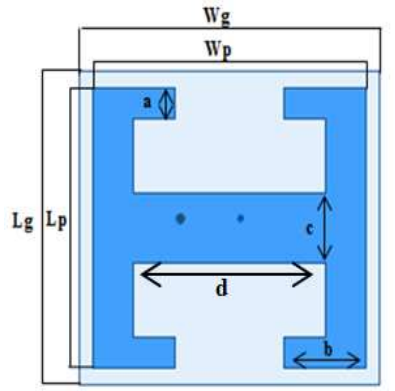

(a)

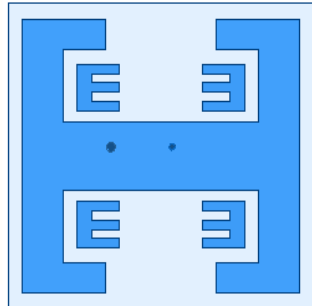

(b)
Fig.6.The proposed antenna (a) Two bonded E resonators (b) Two bonded E loaded by four E-shape MTM resonators.
For the second operation, the proposed antenna is simulated in a One-layer tissue model (skin) and in a three-layer tissue model (skin, fat, and muscle), because of the high values of the dielectric properties of human tissues, the antenna parameters are reduced to reach the desired frequency with the values from table.1.

TABLE 1

THE VALUES PARAMETERS OF THE PROPOSED ANTENNA.

\begin{tabular}{|l|l|l|l|}
\hline Variable & Value(mm) & Variable & Value(mm) \\
\hline $\mathbf{W g}$ & 8 & $\mathbf{a}$ & 0.5 \\
\hline $\mathbf{L g}$ & 7 & $\mathbf{b}$ & 3 \\
\hline $\mathbf{W p}$ & 6.7 & $\mathbf{c}$ & 2.2 \\
\hline $\mathbf{L p}$ & 6 & & \\
\hline
\end{tabular}

The proposed antenna is depth in the upper layer of the skin tissue model, with the dimensions of $100 \mathrm{~mm} \times 100 \mathrm{~mm} \times$ $4 \mathrm{~mm}$ for the single model and $100 \mathrm{~mm} \times 100 \mathrm{~mm} \times$ $23 \mathrm{mmfor}$ the three-layer tissue model, surrounded by a radiation box of dimensions $120 \mathrm{~mm} \times 120 \mathrm{~mm} \times 120 \mathrm{~mm}$ in HFSS, as shown in Fig.7 (a) and (b), and in CST the boundaries are Open add space. Table 2 shows the relative permittivity, conductivity and density for skin, fat, and muscle simulated in $2.45 \mathrm{GHz}$ [24].

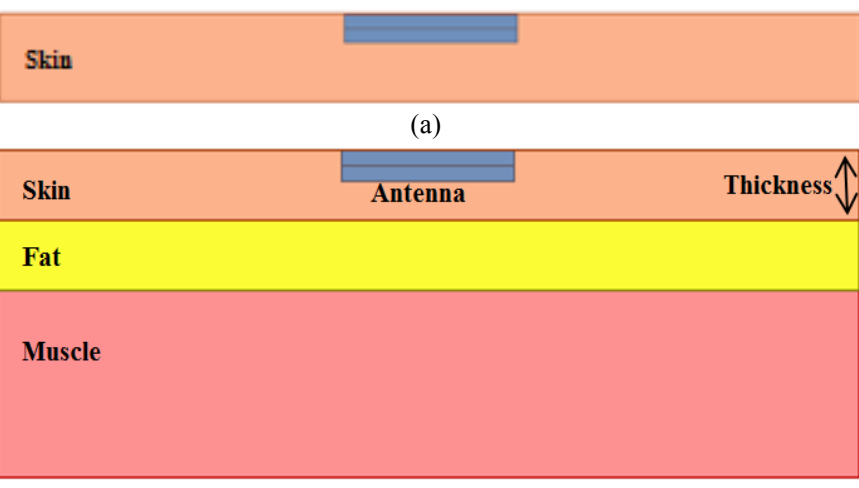

(b)

Fig.7. Antenna with: (a) one-layer tissue model (b) three-layer tissue model.

TABLE 2

DIELECTRIC PROPERTIES OF DIFFERENT TISSUES AT $2.45 \mathrm{GHZ}$.

\begin{tabular}{|l|c|c|c|c|}
\hline Tissues & $\begin{array}{c}\text { Thickness } \\
(\mathbf{m m})\end{array}$ & $\boldsymbol{\varepsilon}_{\boldsymbol{r}}$ & $\boldsymbol{\sigma}(\boldsymbol{S} / \boldsymbol{m})$ & $\begin{array}{l}\text { Density } \\
\left(\boldsymbol{K g} / \mathbf{m}^{\mathbf{3}}\right)\end{array}$ \\
\hline Skin & 4 & 38.0 & 1.44 & 1100 \\
Fat & 4 & 5.28 & 0.1 & 910 \\
Muscle & 15 & 52.7 & 1.74 & 1041 \\
\hline
\end{tabular}

\section{RESULTS AND DISCUSSION}

\section{A. Antenna in free space}

Fig. 8 shows the simulated return loss of the proposed antenna in free space with and without the four E-shape MTM 
resonators. The simulation is done by HFSS software. To validate the results of the proposed antenna obtained with HFSS, we designed the same antenna structure with CST software. The simulation results are shifted as can be seen from the figure, the return loss is $-24.34 \mathrm{~dB}$ and $-32.09 \mathrm{~dB}$ before the addition of the E-shape resonators in HFSS and CST, respectively. For the simulation with the four E-shapes resonators, the return loss values are around $-25 \mathrm{~dB}$ in HFSS and $-32.22 \mathrm{~dB}$ in CST.

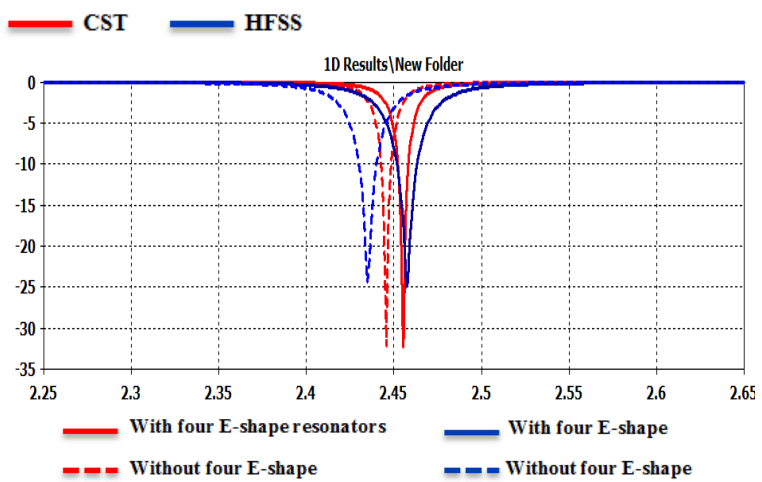

Fig.8.Variation of S-Parameters with Frequency in free space at $2.45 \mathrm{GHz}$.

The different values of the bandwidth (BW) in free space are presented in table 3 .

TABLE 3.

THE BANDWIDTH VALUES.

\begin{tabular}{|l|c|c|}
\cline { 2 - 3 } \multicolumn{1}{c|}{} & CST (MHz) & HFSS (MHz) \\
\hline Without four E-shape & 5.8 & 10.4 \\
\hline With four E-shape & 6 & 11.5 \\
\hline
\end{tabular}

Figure 9 illustrates Farfields gain pattern in free space before and after adding the four MTM E-shape resonators by the HFSS and CST simulator at $2.45 \mathrm{GHz}$, for both principal planes E plane $E(\varphi=0)$ and $\mathrm{H}$ plane $(\varphi=90)$.

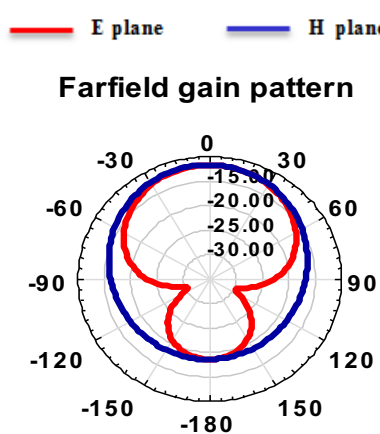

(a)
1D Results \Farfield gain pattern

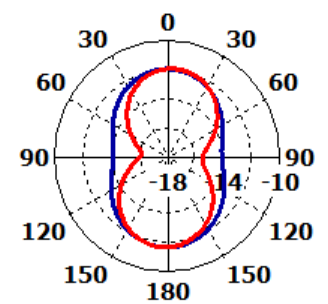

(b)

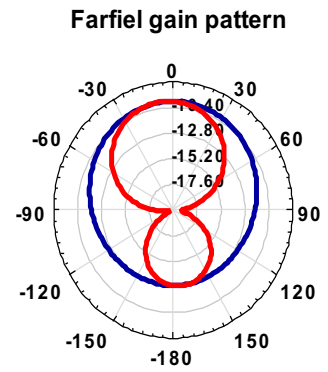

(c)
1D Results\Farfields gain pattern

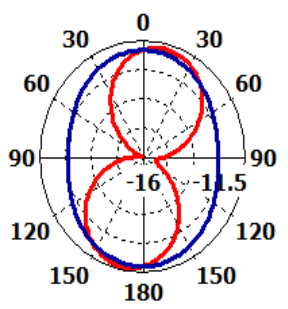

(d)
HFSS: (a)-(c)

CST: (b)-(d)

Fig.9. Farfields radiation gain pattern in free space at $2.45 \mathrm{GHz}$ in HFSS and CST (a)-(b) without four E-shape resonators (c)-(d) with four Eshape resonators.

From the figures, the Farfields gain pattern is bidirectional. The maximum gain values of the proposed antenna are about $11.8 \mathrm{~dB}$ at $2.45 \mathrm{GHz}$ for without the four E-shape resonators in the two stimulators, and with the four E-shape, the values are $-9.79 \mathrm{~dB},-9.84 \mathrm{~dB}$ at $2.45 \mathrm{GHz}$ in HFSS and CST, respectively.

The different results and different main lobe magnitude, main lobe direction, and also the angular width due to the different computational techniques between these two software. HFSS is based on the Finite Element Method (FEM) which is more accurate for designing antennas while CST is based upon Finite Integration in Technique (FIT).

As can see from the results, the addition of the four E-shape resonators improves the bandwidth and also the gain of the proposed antenna.

\section{B. Antenna in one-layer and three-layer tissue models}

The simulated result of the reflection coefficient of the proposed MTM E-shape embedded antenna is presented in Fig.10 for one-layer and three-layer tissue models. For onelayer, the simulated return losses are $-20.27 \mathrm{~dB}$ and $-14.62 \mathrm{~dB}$ in HFSS and CST, respectively. And about the three-layer model, the return losses are $-28.84 \mathrm{~dB}$ in HFSS and -17.39 dB in CST.

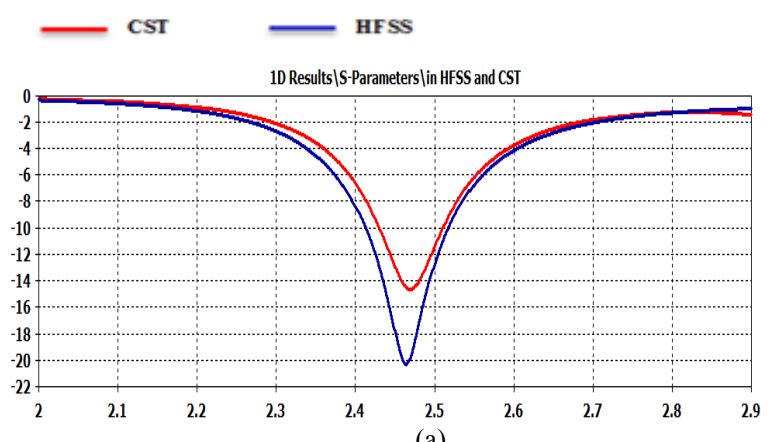

(a) 


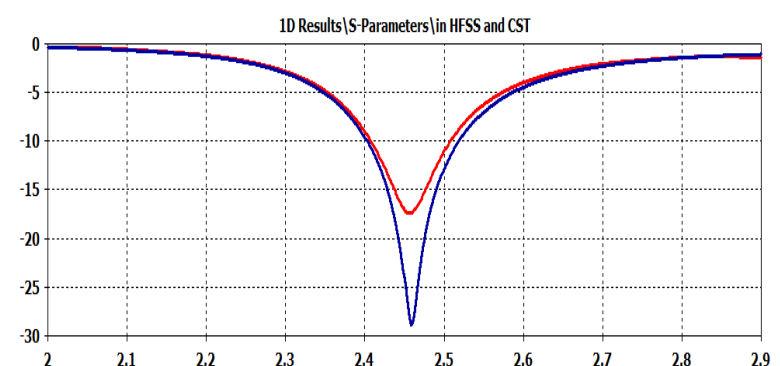

(b)

Fig.10. Variation of S-Parameters (a) one-layer tissue model (b) three layer tissue model.

The table 5 illustrates the bandwidth values of the proposed antenna in different layer models.

TABLE 5 .

THE BANDWIDTH VALUES.

\begin{tabular}{|l|c|c|}
\cline { 2 - 3 } \multicolumn{1}{c|}{} & CST (MHz) & HFSS (MHz) \\
\hline One L-model & 82.3 & 104.2 \\
\hline Three L-model & 100.6 & 116.1 \\
\hline
\end{tabular}

Figure 11 shown Farfields radiation gain pattern for the two planes $\mathrm{E}$ and $\mathrm{H}$ in the one-layer and three-layer tissue models.

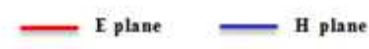

\section{Farfield gain pattern 1 Desults $\backslash$ Farfield gain pattern}

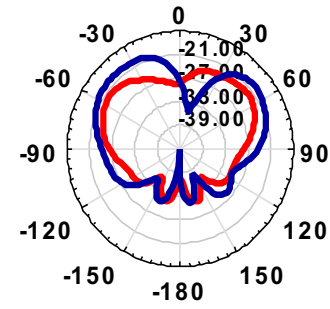

(a)

\section{Farfielf gain pattern}

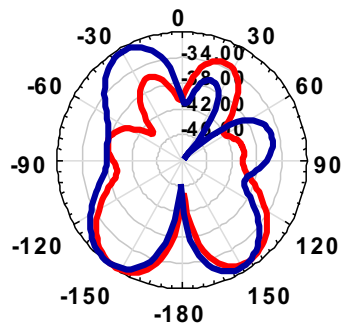

(c)

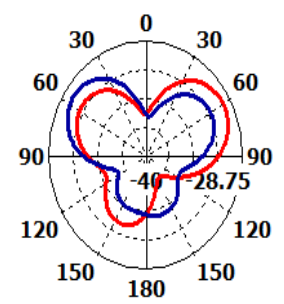

(b)

1D Results \Farfield gain pattern

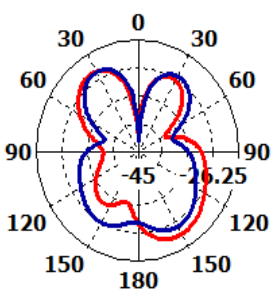

(d)
HFSS: (a)-(c)

CST: (b)-(d)

Fig.11. Farfields radiation gain pattern at $2.45 \mathrm{GHz}$ : in One layer tissue model (a)-(b) and in three layer tissue model (c)-(d).
The maximum gain for one-layer is about $-25.07 \mathrm{~dB}$ and -26 $\mathrm{dB}$ in HFSS and CST, respectively. And for the three-layer, the maximum gain is $-27.58 \mathrm{~dB}$ and $-27.1 \mathrm{~dB}$ in HFSS and CST, respectively.

As can be seen from these plots, the back value of the maximum gain is low in the presence of the human tissues compared to the free space Fig.9. The low gain due to the size of the antenna compared to the size of the human body and also due to its loss environment.

\section{ANTENNA WITH MTM E-INTERDIGITAL RESONATORS}

\section{A. Antenna Design Specifications}

In this part, we replace the four MTM E-shape resonators with another shape of E-interdigital, as shown in Fig.12.This structure is also modeled and simulated by using HFSS software with the same value parameters of the proposed antenna and the same process as indicated in § II.2. The value parameters of the E-shape resonator are $\mathrm{e}=\mathrm{d}=1.5 \mathrm{~mm}$ and the others are shown in fig.13.b.

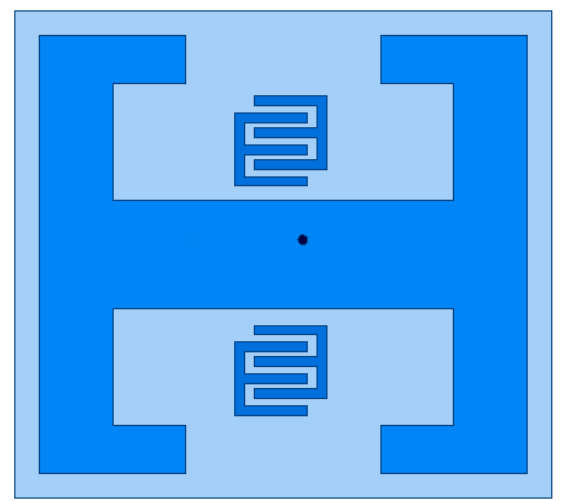

(a)

Unit cell:

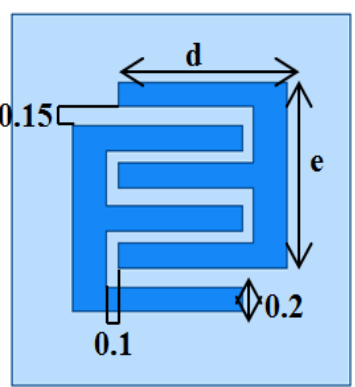

(b)

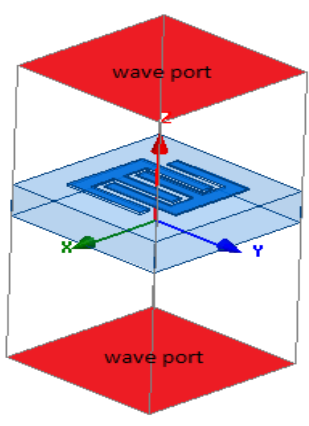

(c)
Fig.12. The proposed antenna (a) Front view (b) The cross sectional view of MTM E- interdigital resonators, (c) Unit cell. 
The $S_{11}$ and $S_{21}$ of the MTM E-interdigital resonator are presented in the Fig. 13.

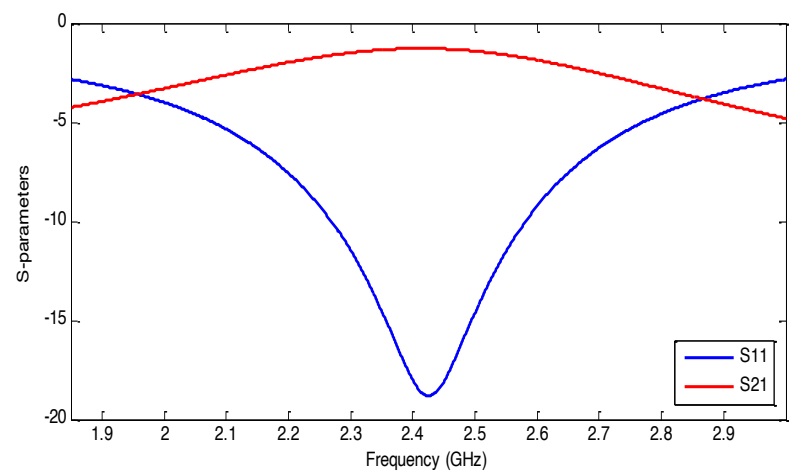

Fig.13. The S-Parameters $\left(S_{11}, S_{7.1}\right)$

To verify the existence of metamaterial in the proposed Einterdigital, we use the same method of Nicolson Ross Weir (NRW) to extract the effective parameters of the MTM: permeability, permittivity and refractive index by using the equations (1)-(4) in $\S$ II.B.

From the S-parameters, we extracted the values of permittivity, permeability, and refractive index, as shown in Figure 14.

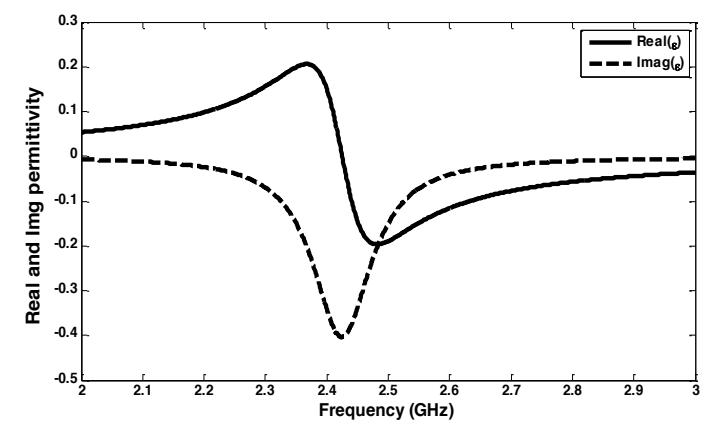

(a)

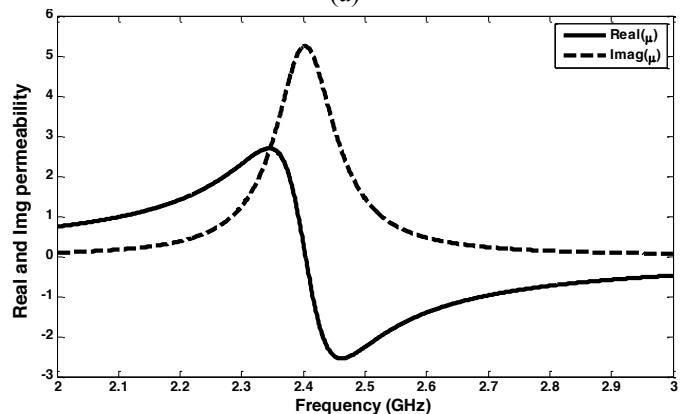

(b)

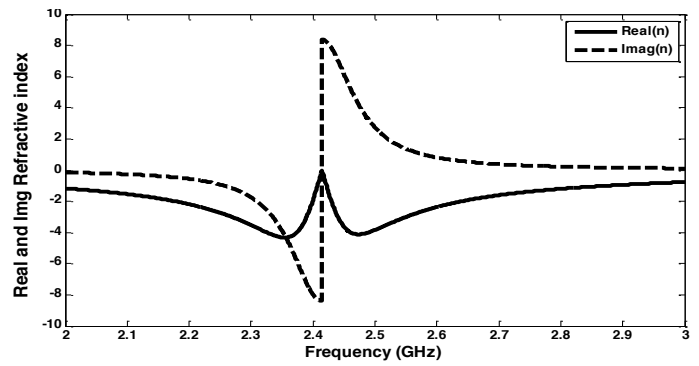

(c)

Fig.14. The real and imaginary part of (a) Permittivity (b) Permeability (c) Refractive index.
The proposed antenna is simulated in free space, in one and three-layer human models by the two stimulators HFSS and CST.

\section{B. Antenna in free space:}

As shown in Fig.15, the reflection coefficient of the proposed antenna is $-18.88 \mathrm{~dB}$ in HFSS and $-24.58 \mathrm{~dB}$ in CST at 2.46 $\mathrm{GHz}$.

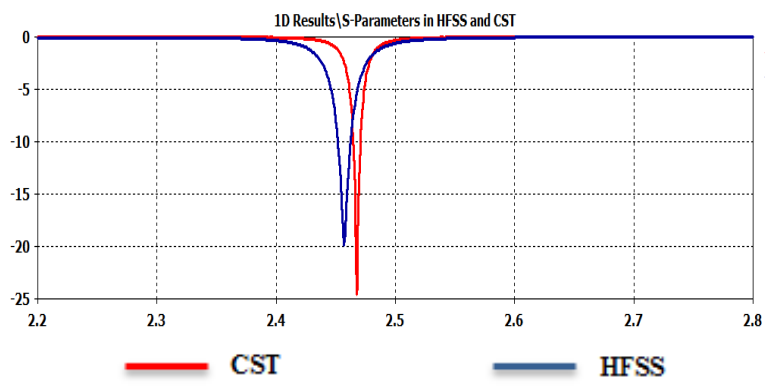

Fig.15. Variation of S-Parameters with Frequency with MTM Einterdigital in free space.

The table 5 illustrates the bandwidth values of the proposed antenna in free space.

TABLE 5 .

THE BANDWIDTH VALUES.

\begin{tabular}{|l|c|c|}
\cline { 2 - 3 } \multicolumn{1}{c|}{} & CST (MHz) & HFSS (MHz) \\
\hline E-interdigital & 10 & 10.6 \\
\hline
\end{tabular}

Figure 16 shows the Farfields gain pattern at $2.45 \mathrm{GHz}$ in free space in HFSS and CST in the two planes E and H. As can see from the figures, the Farfields gain pattern is bidirectional and the maximum gain values at $2.45 \mathrm{GHz}$ are about $-11.16 \mathrm{~dB}$ and $-9.70 \mathrm{~dB}$ in HFSS and CST, respectively.

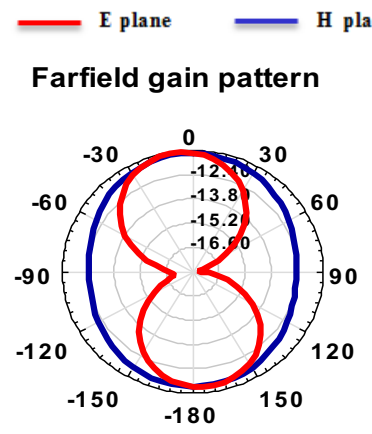

(a)
1D Results \Farfield gain pattern

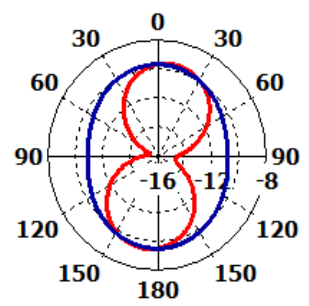

(b)
Fig.16.Farfieldsradiation gain pattern in free space at $2.45 \mathrm{GHz}$ in (a) HFSS (b) CST.

\section{C.Antenna in one and three layer-model:}

The proposed antenna with the resonators E-interdigital takes the same parameter values as indicated in the previous section and table 1 . 
Figure 17 shows the return loss in one and three layer model.

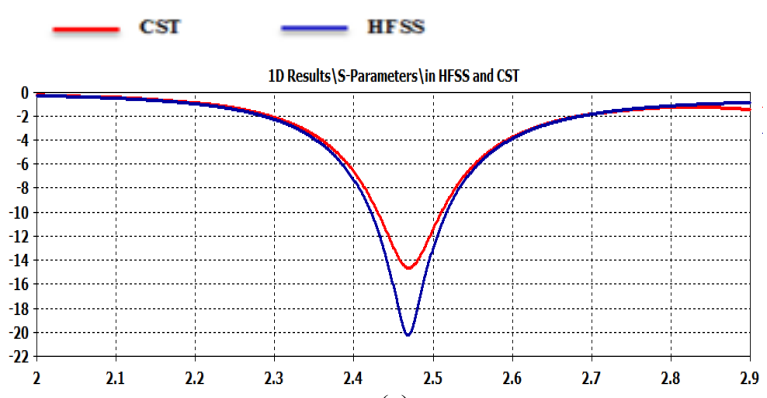

(a)

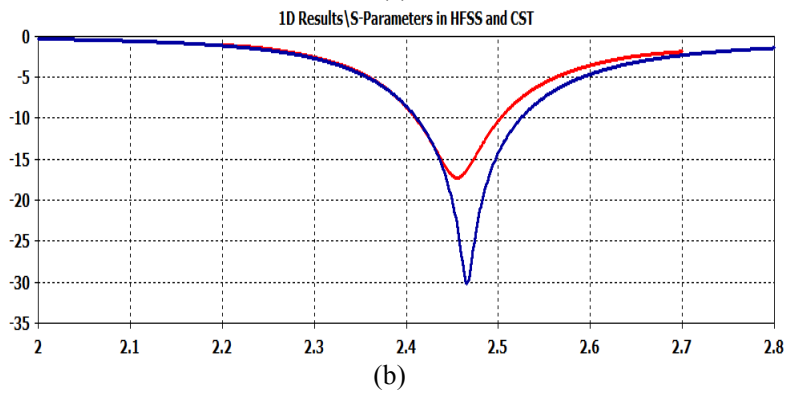

Fig.17. Variation of S-Parameters (a) One-layer tissue model (b) threelayer tissue model.

From Fig.17, the value of the S-Parameters in the one-layer model is $-20.23 \mathrm{~dB}$ and $-14.62 \mathrm{~dB}$ in HFSS and CST, respectively. And about the three-layer model, the return losses are $-30 \mathrm{~dB}$ and $-17.26 \mathrm{~dB}$ in HFSS and CST.

The bandwidth values are presented in Table 6 for one-layer and three-layer models in HFSS and CST.

TABLE 6.

THE BANDWIDTH VALUES.

\begin{tabular}{|l|c|c|}
\cline { 2 - 3 } \multicolumn{1}{c|}{} & CST (MHz) & HFSS (MHz) \\
\hline One L-model & 80.3 & 95.5 \\
\hline Three L-model & 92.6 & 113.9 \\
\hline
\end{tabular}

Figure 18 illustrates the Farfields radiation pattern for the two planes $\mathrm{E}$ and $\mathrm{H}$ in the one-layer and three-layer tissue models in HFSS and CST.

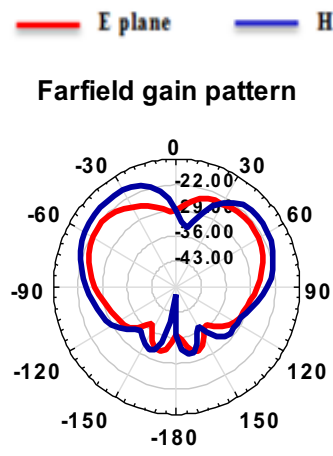

(a)
1D Results $\backslash$ Farfield gain pattern

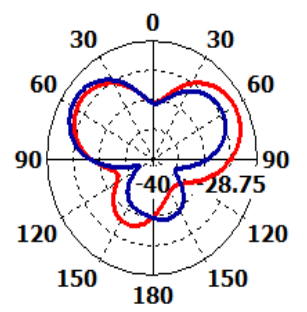

(b)

\section{Farfield gain pattern 1D Results \Farfield gain pattern}

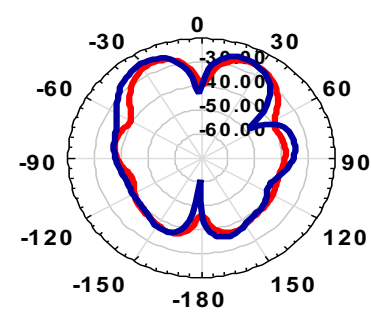

(c)

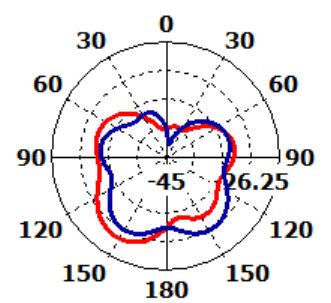

(d)
HFSS: (a)-(c)

CST: (b)-(d)

Fig.18. Farfields radiation gain pattern at $2.45 \mathrm{GHz}$ in One-layer tissue model (a)-(b) and in three-layer tissue model (c)-(d).

The maximum gain values $-25.39 \mathrm{~dB}$ and $-26 \mathrm{~dB}$ for the onelayer model in HFSS and CST, respectively. And about the three-layer model, the maximum gain is around $-28 \mathrm{~dB}$ in HFSS and $-27 \mathrm{~dB}$ in CST.

\section{PATIENT SAFETy (BIocompatibility) AND SAR}

The implantable medical devices content not only the antenna but contains other components like sensors, batteries... So to eliminate direct contact with the human body, all components of the IMD are encased in biocompatible materials. There are many biocompatible materials in literature, Silica [25], Ceramic Alumina $\left(\mathrm{Al}_{2} \mathrm{O}_{3}\right)$ [26-27], Zirconia $\left(\mathrm{ZrO}_{2}\right)$ [28], Parylene-C [29]...

The specific absorption rate (SAR) evaluates to observe the sensitivity of human tissues to electromagnetic energy, it is necessary to specify the maximum acceptable input power to the antenna [30]. The SAR limit specified in IEEE C95.1: 1999 is $1.6 \mathrm{~W} / \mathrm{Kg}$ in a SAR 1 -g averaging mass while that specified in IEEE C95.1: 2005 has been updated to $2 \mathrm{~W} / \mathrm{Kg}$ in a 10 -g averaging mass [31].

SAR is calculated by:

$$
S A R=\frac{\sigma}{\rho}|E|
$$

Where $\mathrm{E}$ is the root mean square RMS of the induced electric field $(\mathrm{V} / \mathrm{m})$ and $\rho$ is the mass density of the tissue $\left(\mathrm{Kg} / \mathrm{m}^{3}\right)$. The SAR values are calculated by the average method of CST IEEE C95.3 and HFSS in the skin tissue at the frequency of $2.45 \mathrm{GHz}$.

The SAR is calculated first with the default input power of 1 $\mathrm{W}$ in HFSS and $0.5 \mathrm{~W}$ in CST for the two proposed MTM resonators, four E-shape and E- interdigital resonators. 
Figures19 and 20 show the distribution of SAR for the Two MTM resonators, E-shape and E- interdigital resonators in One-layer skin with CST and HFSS, respectively.

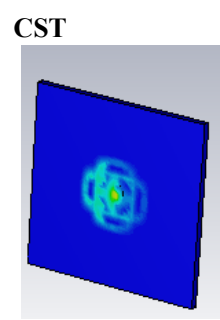

HFSS

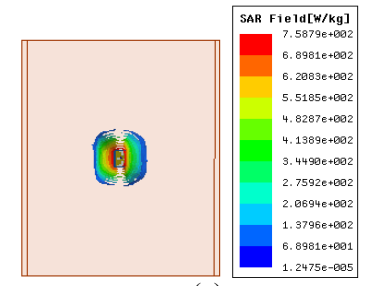

(c)

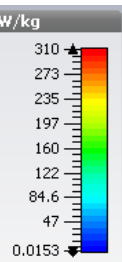

(a)

Fig.19. SAR distribution of four E-shape resonators in the skin in CST and HFSS (a)-(c) $1 \mathrm{~g}(\mathrm{~b})-(\mathrm{d}) 10 \mathrm{~g}$.

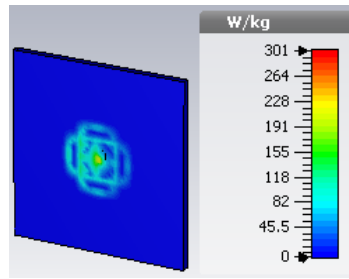

(a)

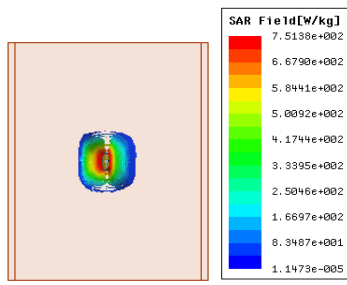

(c)

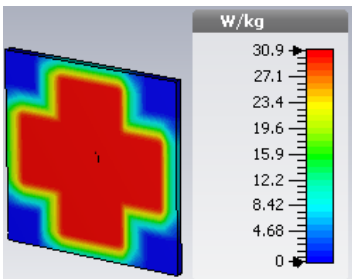

(b)

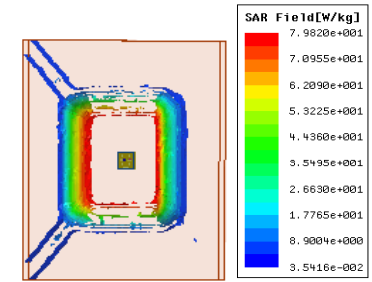

(d)
Fig.20. SAR distribution of E-interdigital resonators in the skin in CST and HFSS (a)-(c) $1 \mathrm{~g}$ (b)-(d) $10 \mathrm{~g}$.

The maximum SAR values are presented in Table 8. These values are not acceptable and harm human tissues. So we need to change the reference power values to preserve the standards.

TABLE 8

SIMULATED SAR IN 1-G AND 10-G OF SKIN TISSUE OBTAINED FROM CST AND HFSS FOR $1 \mathrm{~W}$.

\begin{tabular}{|l|c|c|c|c|}
\cline { 2 - 5 } \multicolumn{2}{c|}{} & \multicolumn{4}{c|}{$\begin{array}{c}\text { CST } \\
(\mathbf{0 . 5} \text { W) }\end{array}$} & \multicolumn{1}{c|}{$\begin{array}{c}\text { SFSS } \\
(\mathbf{1} \text { W) }\end{array}$} \\
\cline { 2 - 6 } \multicolumn{1}{c|}{ SAR/Kg) } \\
\hline Fours of Tissue & 1 g-Avrg & 10 g-Avrg & 1 g-Avrg & 10 g-Avrg \\
\hline E-interdigital & 301 & 30.9 & 751 & 79.8 \\
\hline
\end{tabular}

So, to get the standards values we have to change the reference power value. The input power values for the two MTM resonators (E-shape and E- interdigital) become $1.5 \mathrm{~mW}$ for HFSS, and $2.5 \mathrm{~mW}$ for CST.

The new values of the SAR are $1.51 \mathrm{~W} / \mathrm{kg}$ and $0.16 \mathrm{~W} / \mathrm{Kg}$ in HFSS and $1.55 \mathrm{~W} / \mathrm{Kg}, 0.15 \mathrm{~W} / \mathrm{Kg}$ in CST for $1 \mathrm{~g}$ and $10 \mathrm{~g}$, respectively for the MTM E-shape resonators, and about the MTM E- interdigital are $1.13 \mathrm{~W} / \mathrm{Kg}$ and $0.12 \mathrm{~W} / \mathrm{Kg}$ in HFSS and $1.21 \mathrm{~W} / \mathrm{Kg}, 0.12 \mathrm{~W} / \mathrm{Kg}$ in CST, averaged $1 \mathrm{~g}$ and $10 \mathrm{~g}$, respectively.

Table 9 illustrates the different values of the size, the gain and the SAR, in the literature and our work of E-shape and Einterdigital MTM resonators on average for $1 \mathrm{~g}$ and $10 \mathrm{~g}$ of tissue with the default input power of $1 \mathrm{~W}$.

TABLE 9

COMPARISON OF THE PROPOSED ANTENNA WITH SOME WORKS IN LITERATURE

\begin{tabular}{|c|c|c|c|c|}
\hline \multirow{2}{*}{$\begin{array}{l}\text { Freq } \\
\text { (GHz) }\end{array}$} & \multirow{2}{*}{$\begin{array}{l}\text { Size } \\
\left(\boldsymbol{m m ^ { 3 }}\right)\end{array}$} & \multirow{2}{*}{$\begin{array}{l}\text { Gain } \\
\text { (dBi) }\end{array}$} & \multicolumn{2}{|c|}{ SAR(W/Kg) } \\
\hline & & & $1 \mathrm{~g}$ & $10 \mathrm{~g}$ \\
\hline 2.45 & $7 \times 6 \times 0.256$ & -9.81 & 524.3 & NAN \\
\hline 0.92 & $58 \times 40 \times 0.8$ & -34 & 881.5 & NAN \\
\hline 2.45 & $12 \times 12 \times 0.635$ & -22.29 & 591.40 & 82.71 \\
\hline & & -25.3 & 758 & 80.1 \\
\hline 2.45 & $8 \times 7 \times 0.635$ & -25 & 751 & 79.8 \\
\hline
\end{tabular}

4-E: four E-shape resonators

E-inter: E-interdigital.

\section{V.CONCLUSION}

This paper presents the proposed antenna with two different metamaterial resonators, the first one with four E-shapes resonators and the second with E- interdigital resonators. The overall size of antennas is $8 \times 7 \times 1.27 \mathrm{~mm}^{3}$, operate at 2.45 $\mathrm{GHz}$ for ISM bands. The two proposed antennas are simulated in free space, one-layer and three-layer tissue models. The simulation results are reasonable and are validated with two stimulators. The gain value of the proposed antennas is reduced from the free space to the human body because of the lossy nature. The SAR values are simulated in the skin tissue by two software CST and HFSS, and these values are acceptable by IEEE C95.1: 1999. 


\section{ACKNOWLEDGMENTS}

This work was financially supported by the Directorate General of Scientific Research and Technological Development (DGRSDT) under the authority of the Ministry of higher education and scientific research MESRS.

\section{REFERENCES}

[1] R. Alrawashdeh, "Implantable antennas for biomedical applications," $\mathrm{Ph}$. D. Dissertation, univ. Liverpool, 2005.

[2] A. Kiourti, and al., "Miniature implantable antennas for biomedical telemetry: From simulation to realization," IEEE transactions on biomedical engineering, vol. 59, no. 11, pp. 3140-3147, 2012.

[3] Keltouma Nouri, Tayeb Habib Chawki Bouazza, Boubakar Seddik Bouazza, Mehdi Damou, Kada Becharef, and Salima Seghier, "Design of substrate integrated waveguide multi-band slots array antennas, "International Journal of Information and Electronics Engineering, Vol. 6, no. 4, July 2016.

[4] Abes Turjiya, Nouri Keltouma, Bouazza Boubakar Seddik, and Becharef Kada, "Performance of a New Design Based on SubstrateIntegrated Waveguide Slotted Antenna Arrays for Dual-Band Applications $(\mathrm{Ku} / \mathrm{K})$, ,Journal of Communications Software and Systems, vol. 16, no. 2, pp. 131-142, 2020.

[5] A. Kiourti, K. A. Psathas, and K.S. Nikita, "Implantable and ingestible medical devices with wireless telemetry functionalities: A review of current status and challenges," Bioelectromagnetics, vol. 35, no.1, pp. $1-15,2014$

[6] L. J. Xu, Y. X. Guo, and W. Wen, "Dual-band implantable antenna with open-end slots on ground." IEEE Antennas and Wireless Propagation Letters, vol. 11, pp. 1564-1567, 2012.

[7] R. Waterhouse, "Small microstrip patch antenna," Electron. Lett, vol. 31, no. 8, pp. 604-605, 1995.

[8] T. Ali, and R. C. Birdar, "A compact multiband antenna using $\lambda / 4$ rectangular stub loaded with metamaterial for IEEE $802.11 \mathrm{~N}$ and IEEE802.16 E." Microwave and Optical Technology Letters, vol. 59, no. 5, pp. 1000-1006, 2017.

[9] J. Kim, and Y. Rahmat-Samii, "Implanted antennas inside a human body: Simulations, designs, and characterizations, "IEEE Transactions on microwave theory and techniques, vol. 52, no. 8, pp. 1934-1943, 2004.

[10] A. Kiourti, and K. S. Nikita, "Miniature scalp-implantable antennas for telemetry in the MICS and ISM bands: design, safety considerations and link budget analysis," IEEE Transactions on antennas and propagation, vol. 60, no. 8, pp. 3568-3575, 2012.

[11] Barrett, P. John, and S. A. Cummer, "Design and full characterization of planar active magnetic RF metamaterials," IEEE Antennas and Wireless Propagation Letters, vol. 14, pp. 943-946, 2015.

[12] Kada Becharef, Keltouma Nouri, Habib Kandouci, Boubakar Seddik Bouazza, Mehdi Damou, Tayeb Habib Chawki Bouazza, "Design and Simulation of a Broadband Bandpass Filter Based on Complementary Split Ring Resonator Circular "CSRRs"," Wireless Personal Communications, vol. 111, no. 3, pp. 1341-1354, April 2020.

[13] V. G. Veselagos, "The Electrodynamics of Substances with Simultaneously Negative Values of $\epsilon$ and $\mu$," Physics-Uspekhi, vol. 10, no. 4, pp. 509-514, 1968.

[14] S. Jarchi, O. Soltan-Mohammadi, and J. Rashed-Mohassel. "A planar, layered ultra-wideband Metamaterial absorber for microwave frequencies," International Journal of Engineering, vol. 30, no. 3, pp. 338-343, 2017.

[15] Y. Dong and T. Itoh. "Metamaterial-based antennas," Proceedings of the IEEE, vol. 100, no.7, pp. 2271-2285, 2012.
[16] BECHAREF Kada, ABES Turkiya, NOURI Keltouma,"Application of Metamaterials for the Design of Antenna," 2019 6th International Conference on Image and Signal Processing and their Applications (ISPA), pp. 1-4, Mostaganem, Algeria, 2019, https://ieeexplore.ieee.org/document/8966859

[17] Becharef Kada, Damou Mehdi, Bouazza Boubakar Seddik, Nouri Keltouma, "Balance Microwave LPF Responses with CSRRs," Microwaves and RF, pp. 50-52, July 2017.

[18] M. F. Khan, and M. J. Mughal, "Tunable metamaterials by varying the inductance and capacitance of S-shaped resonator," 2009 3rd IEEE International Symposium on Microwave, Antenna, Propagation and EMC Technologies for Wireless Communications. IEEE, pp.140-143, Lahore, Pakistan, April 2009.

[19] A. Dadgarpour, A. Zarghooni, B. S. Virdee, and al, "Millimeter-wave high-gain SIW end-fire bow-tie antenna," IEEE Transactions on Antennas and Propagation, vol. 63, no.5, pp. 2337-2342, 2015.

[20] M. Zada, I. A. Shah, and H. Yoo, "Metamaterial-loaded compact highgain dual-band circularly polarized implantable antenna system for multiple biomedical applications,"IEEE Transactions on Antennas and Propagation, vol. 68, no. 2, pp. 1140-1144, 2019.

[21] D.Chaturvedi, and S.Raghavan,"A Compact Metamaterial-Inspired Antenna for WBAN Application," Wireless Personal Communications, vol. 105, no 4, pp. 1449-1460, 2019.

[22] S. Goswami, and D. C. Karia,"A metamaterial-inspired circularly polarized antenna for implantable applications," Engineering Reports, vol. 2, no 10, pp. e12251, 2020.

[23] M. Dhillon, and P. Dimri, "Design of Metamaterials in HFSS and Extraction of Permittivity and Permeability using NRW Method," Int. J. Electron. Electr.Comput.Syst, vol. 4, pp. 38-43, 2015.

[24] Z. J. Yang, S. Q. Xiao, L. Zhu, B. Z. Wang, and H. L. Tu, "A circularly polarized implantable antenna for 2.4-GHz ISM band biomedical applications,"IEEE Antennas and Wireless Propagation Letters, vol. 16, p. 2554-2557, 2017.

[25] M. Ali, E. Bashar, and K. Hosain, "Circural planner inverted- F antenna for implantable biomedical applications,"2nd International Conference on Electrical and Electronic Engineering (ICEEE), pp. 1-4, Dec2017.

[26] M. Nachiappan, T. Azhagarsamy, "Design and development of dualspiral antenna for implantable biomedical applications,"Biomedical Research, vol. 28, no. 12, pp. 5237-5240, 2017.

[27] N. Challa, S. Raghavan, "Design of broadband implantable loop antenna for human brain applications,"International Conference on Emerging Trends in Engineering, Technology and Science, pp. 1-5, 2016

[28] A. Kaka, M. Toycan. "Miniaturized stacked implant antenna design at ISM band with biocompatible characteristics," COMPEL: The International Journal for Computation and Mathematics in Electrical and Electronic Engineering, vol. 34, no. 4, pp. 1270-1285, 2015.

[29] Z. Duan, Y. Guo, M. Je, D. Kwong, "Design and in vitro test of a differentially fed dual-band implantable antenna operating at MICS and ISM bands," IEEE Transactions on Antennas and Propagation, vol. 62, no.5, pp. 2430-2439, 2014.

[30] Nadh, B. Prudhvi, B. T. P. Madhav, and M. Siva Kumar. "Design and analysis of dual band implantable DGS antenna for medical applications." Sādhanā, vol. 44, no. 6, pp. 131, 2019.

[31] W. H. Bailey, Ralf, G. Bushber, Jerrold, \& al, "Synopsis of IEEE Std C95. 1-2019 IEEE Standard for Safety Levels with Respect to Human Exposure to Electric, Magnetic, and Electromagnetic Fields, $0 \mathrm{~Hz}$ to 300 GHz"." IEEE Access, vol. 7, pp. 171346-171356, 2019.

[32] M. Wang, H. Liu, P. Zhang, \& al, "Broadband Implantable Antenna for Wireless Power Transfer in Cardiac Pacemaker Applications," IEEE Journal of Electromagnetics, $R F$ and Microwaves in Medicine and Biology, 2020.

[33] F. Faisal, M. Zada, A. Ejaz, Y. Amin, \& al, "A miniaturized dual-band implantable antenna system for medical applications,"IEEE 
Transactions on Antennas and Propagation, vol. 68, no. 2, pp. 11611165, 2019. 
Figures

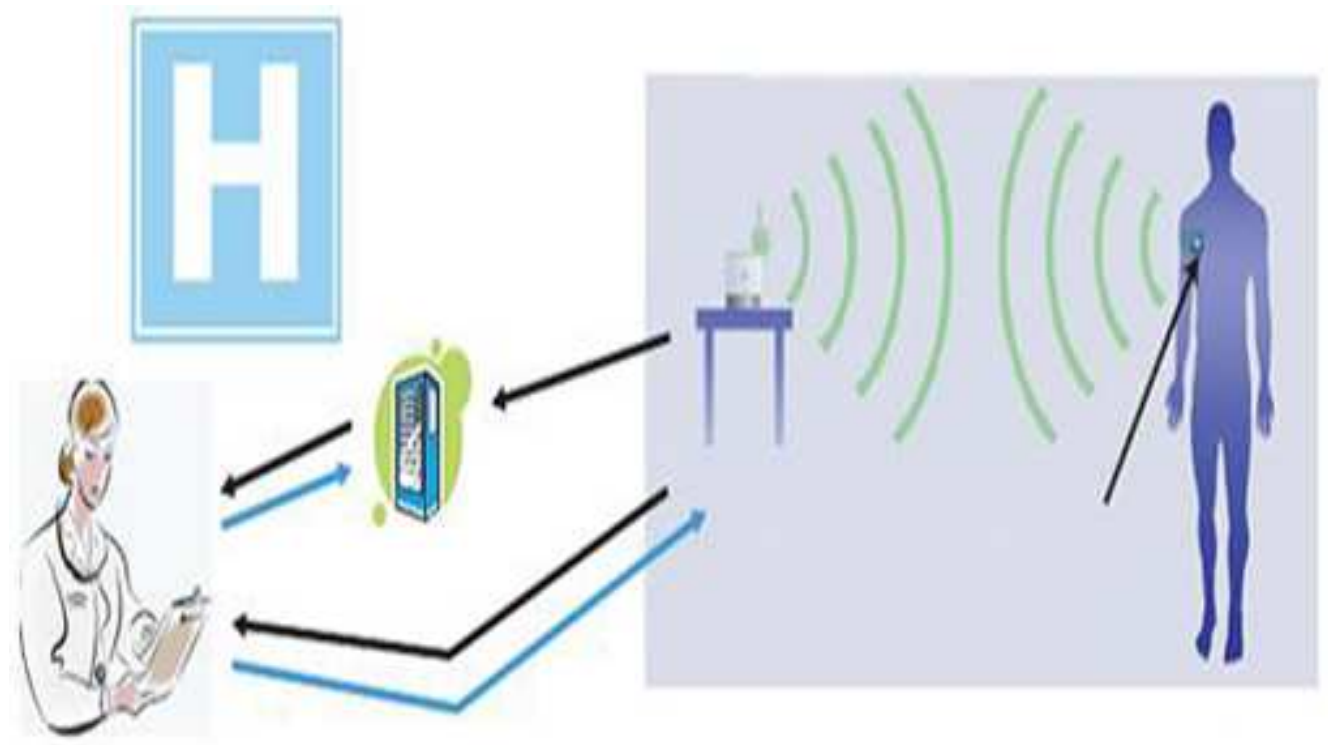

Figure 1

Illustration of a health monitoring system [1]. 


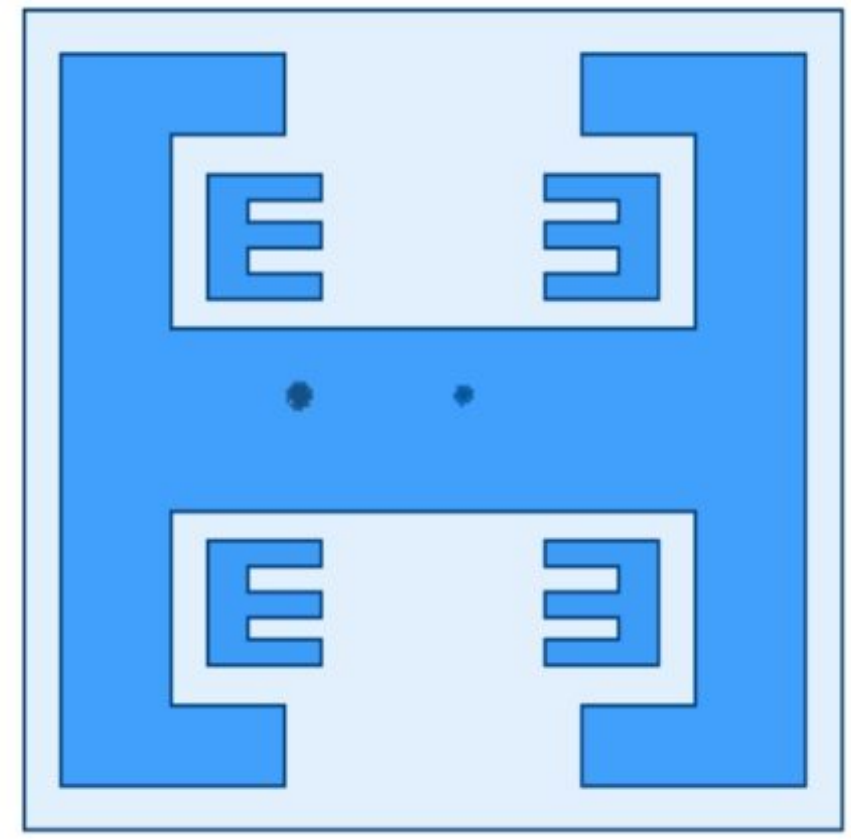

(a)

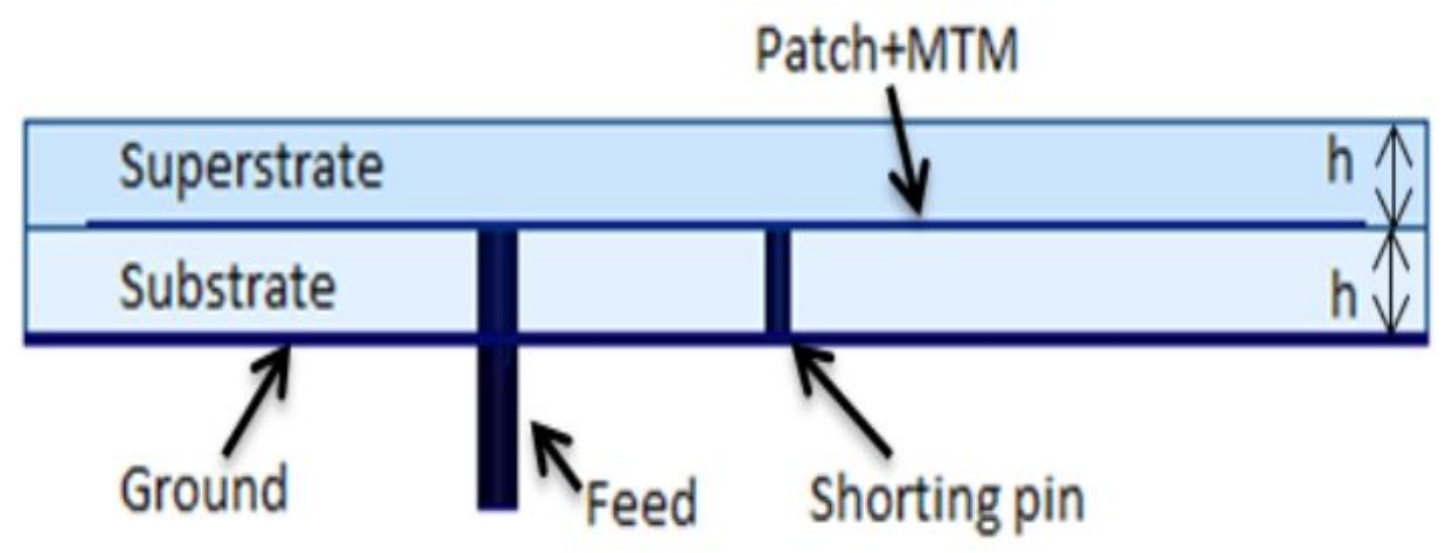

(b)

Fig.2. The proposed antenna (a) Two bonded E loaded by MTM four Eshape resonators (b) Side view.

Figure 2

Please view the caption in the figure. 


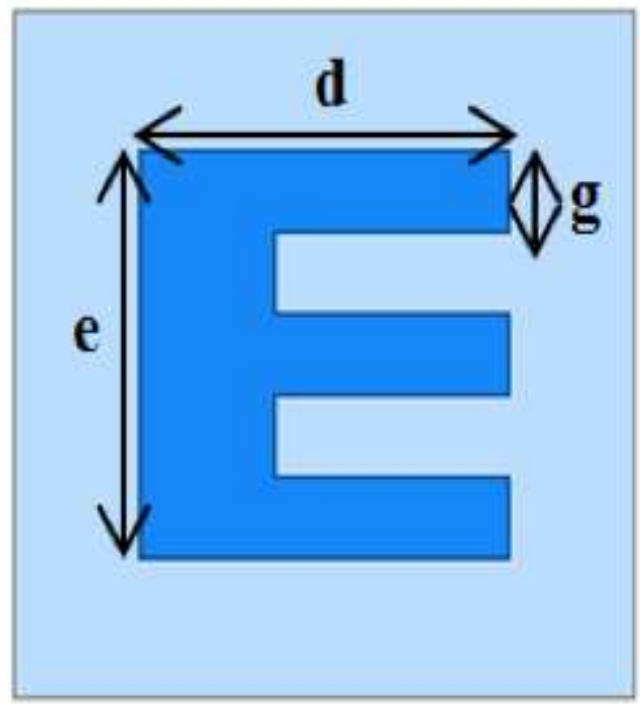

(a)

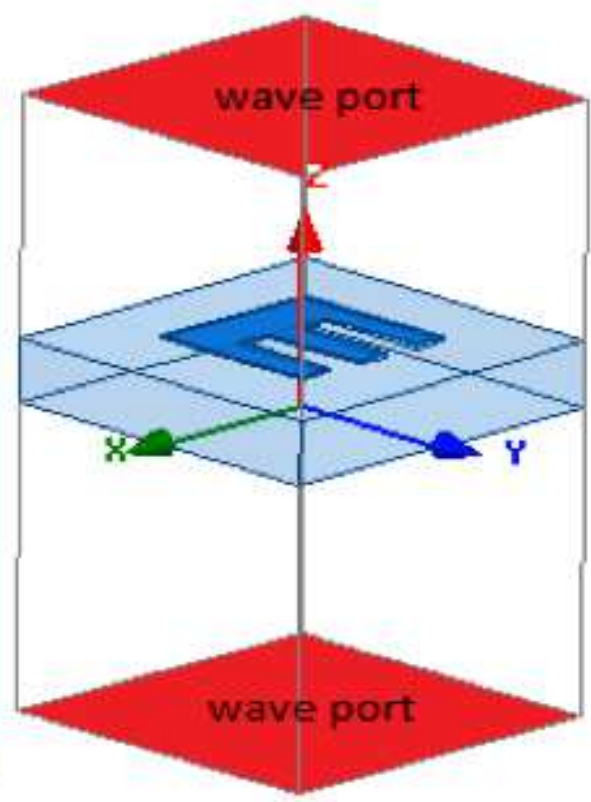

(b)

\section{Figure 3}

(a) The cross sectional view of MTM E-shape resonator, (b) Unit cell.

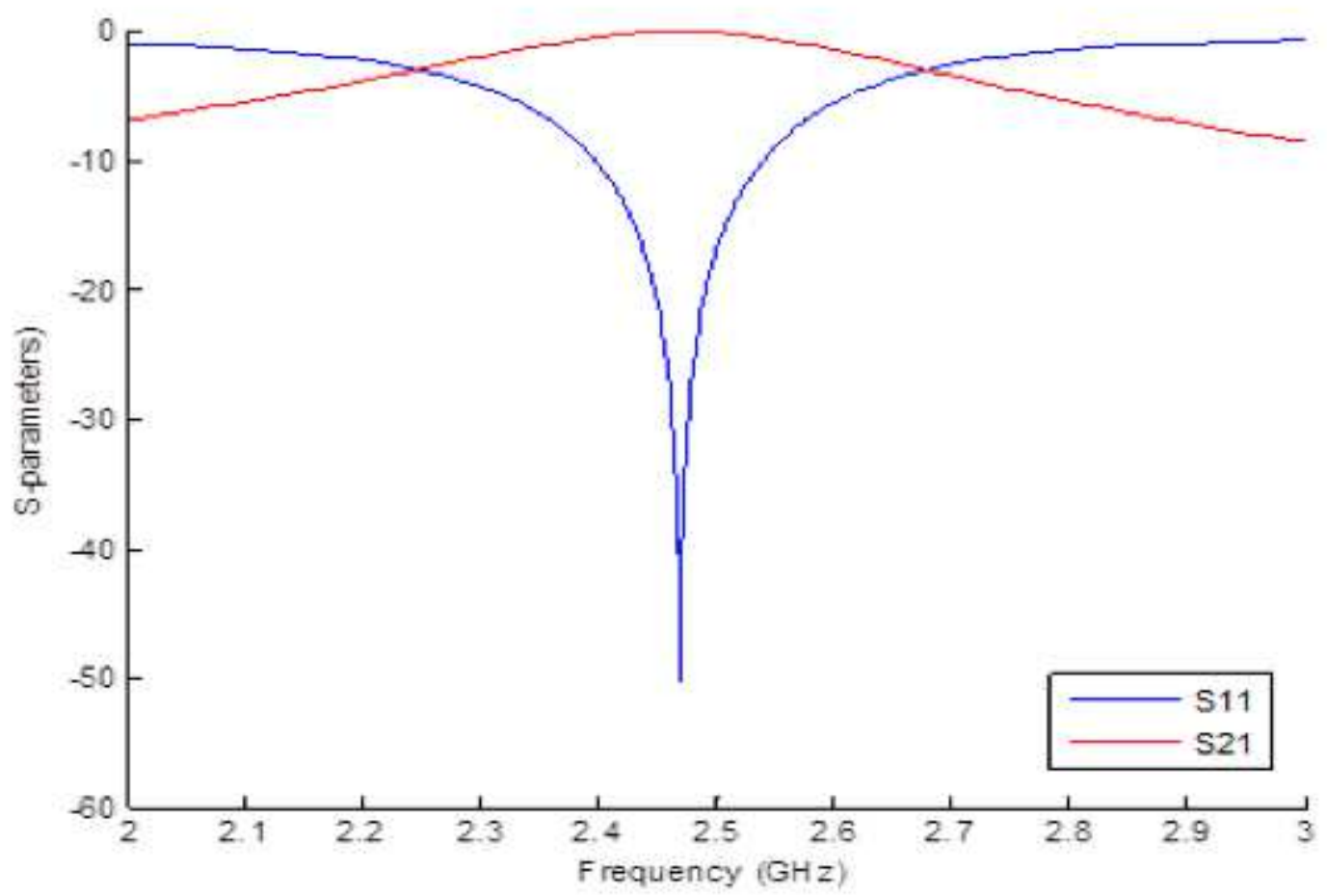

Figure 4

S-parameters (S11, S21) 


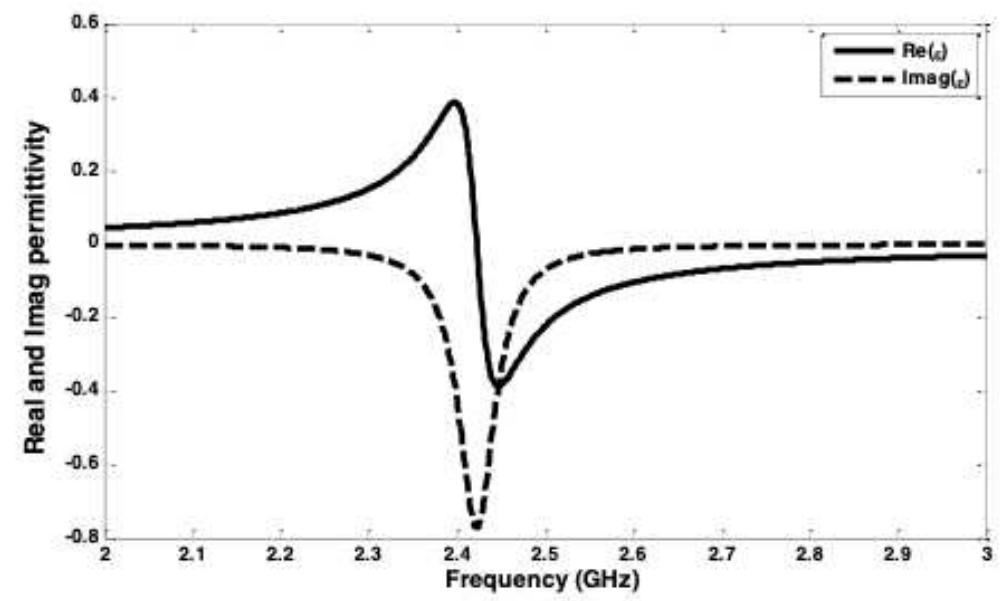

(a)

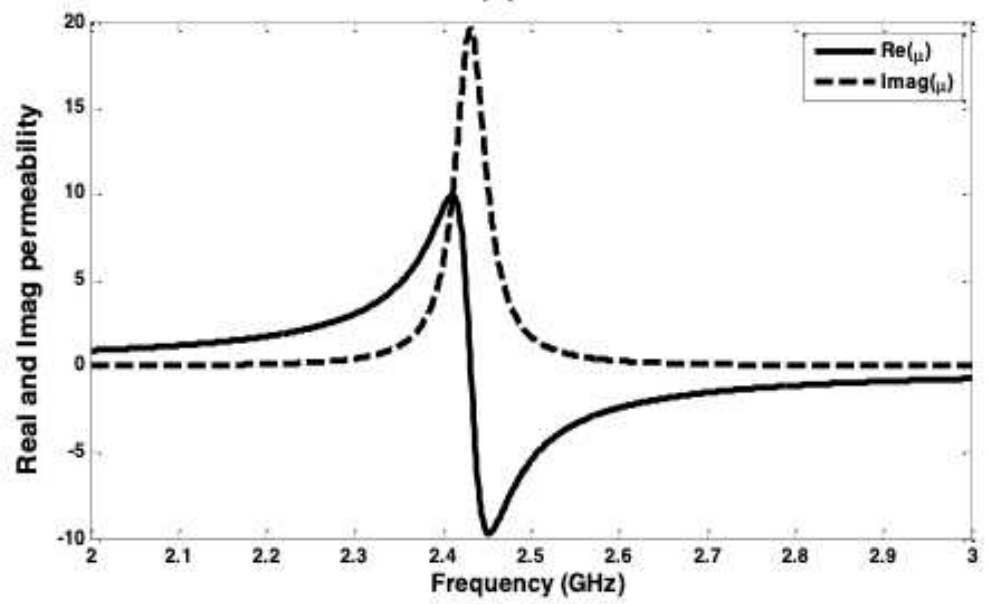

(b)

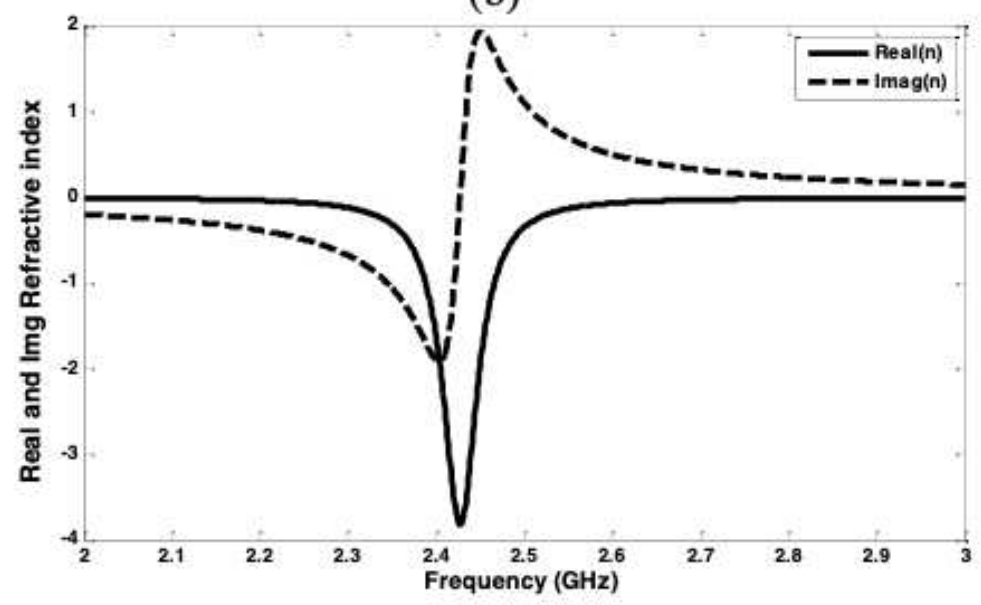

(C)

Figure 5

the real and imaginary part of (a) Permittivity (b) Permeability and (c) Refractive index. 


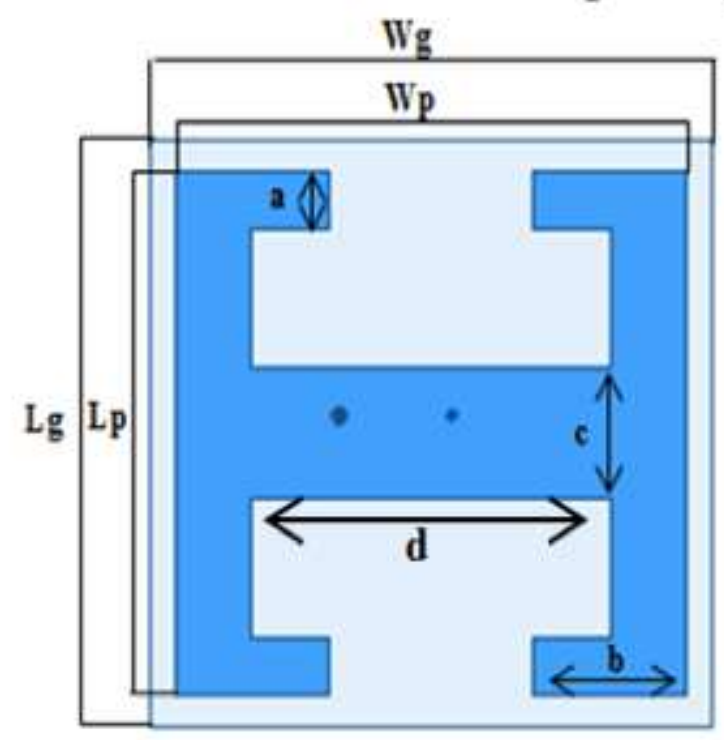

(a)

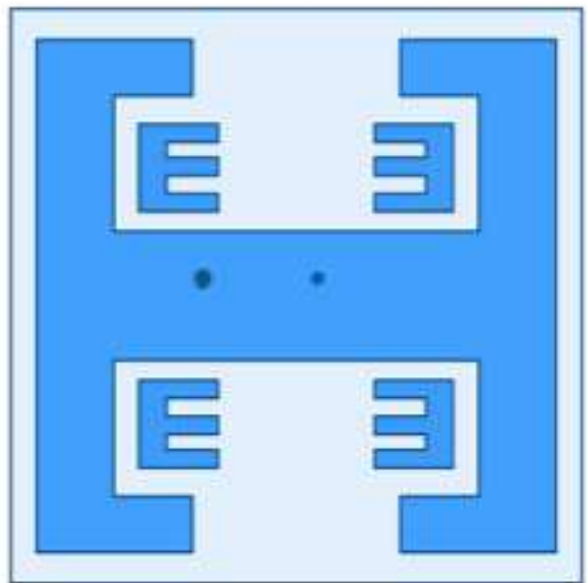

(b)

Figure 6

The proposed antenna (a) Two bonded E resonators (b) Two bonded E loaded by four E-shape MTM resonators

\section{Skin}

(a)

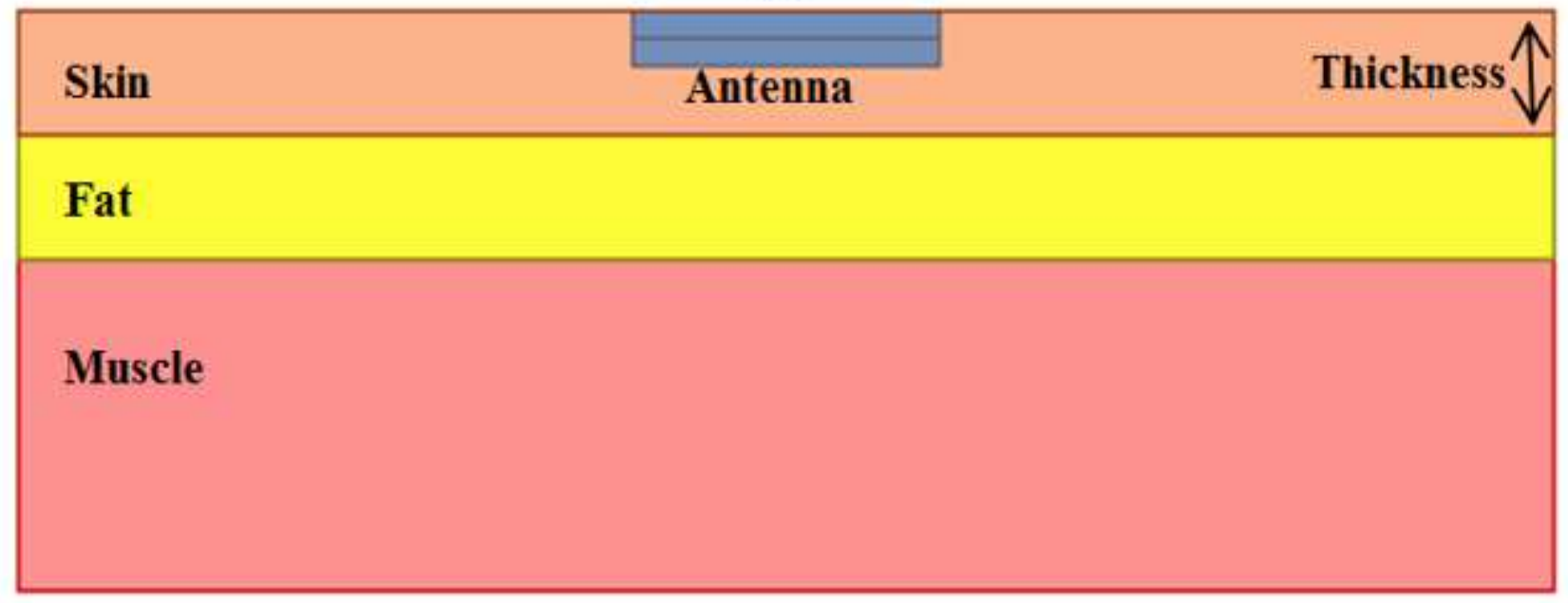

(b)

\section{Figure 7}

Antenna with: (a) one-layer tissue model (b) three-layer tissue model. 


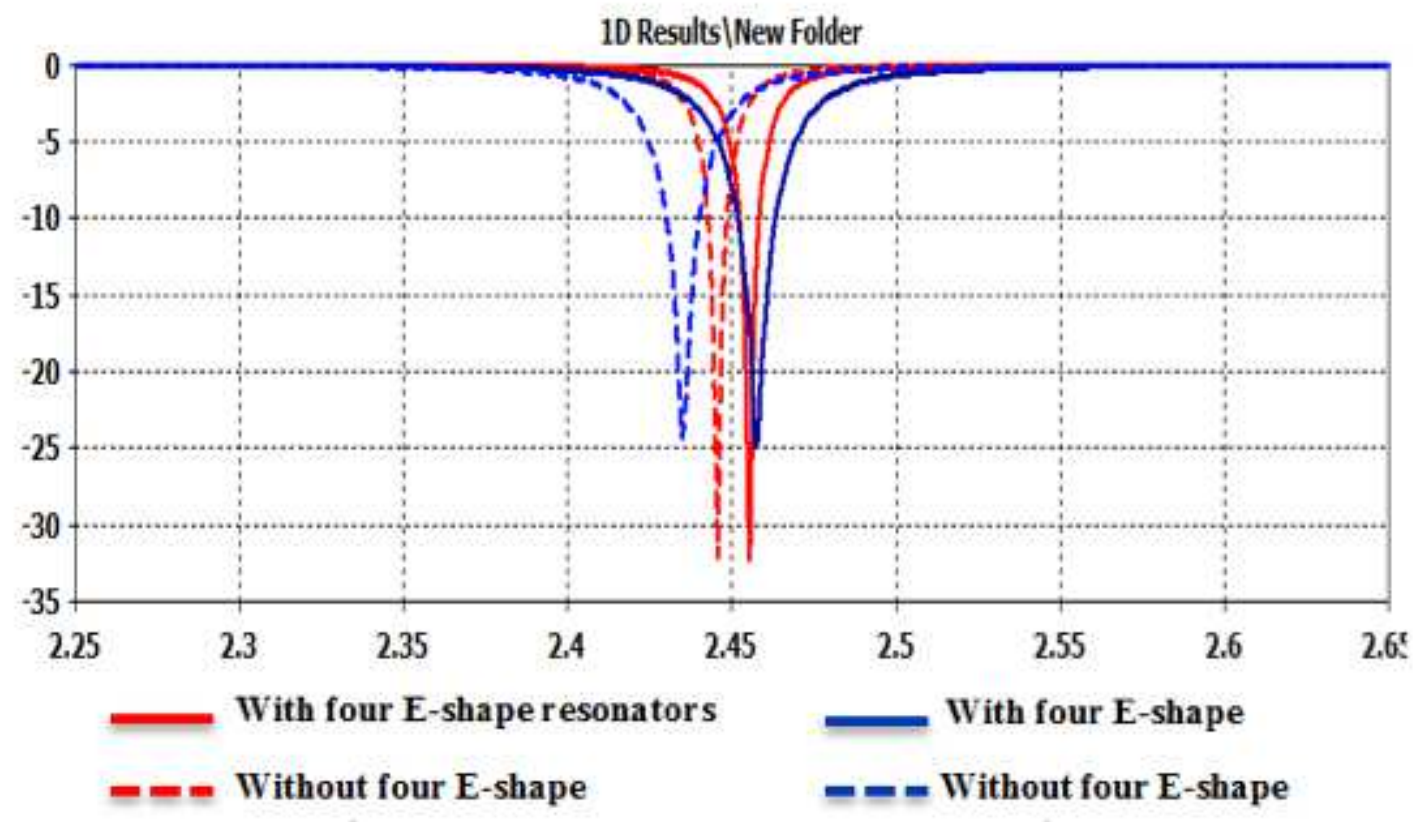

Figure 8

Variation of S-Parameters with Frequency in free space at $2.45 \mathrm{GHz}$. 
E plane $\quad$ H plane

Farfield gain pattern 1D Results $\backslash$ Farfield gain pattern

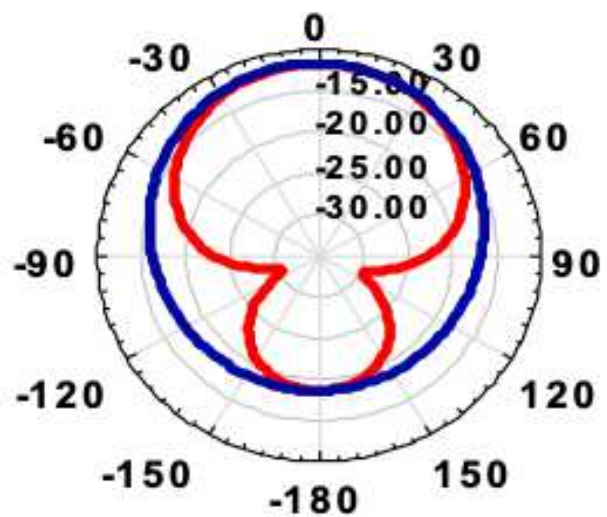

(a)

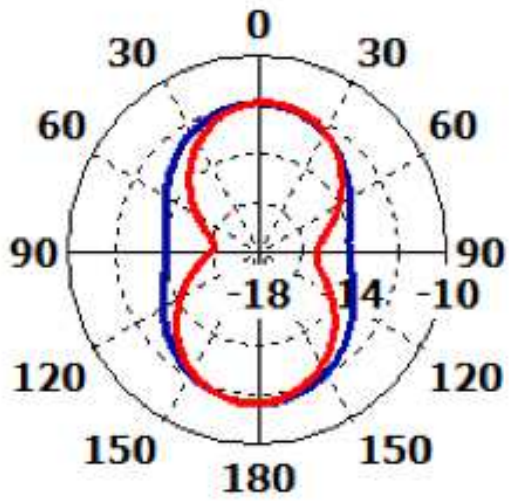

(b)
Farfiel gain pattern

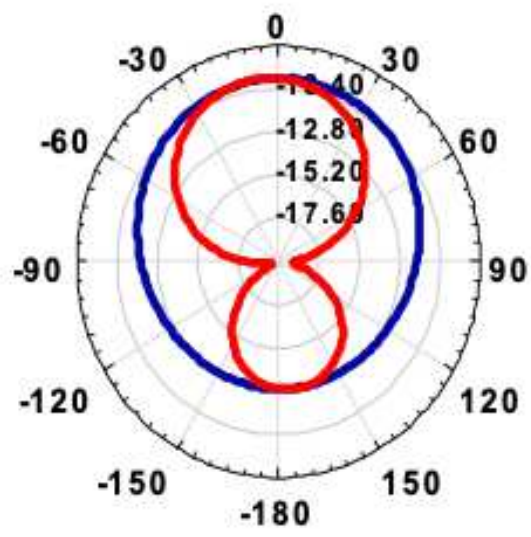

(c)
1D Results $\backslash$ Farfields gain pattern

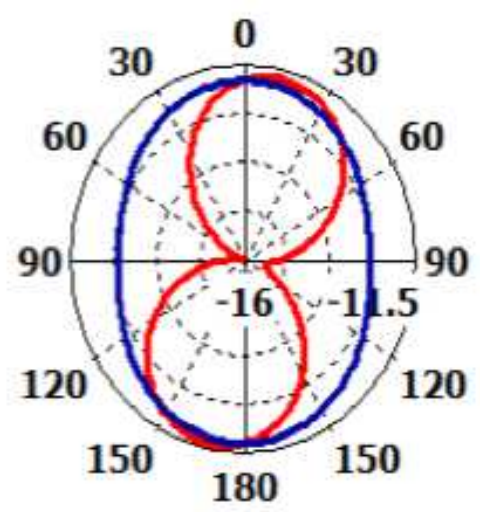

(d)

HFSS: (a)-(c)

CST: (b)-(d)

\section{Figure 9}

Farfields radiation gain pattern in free space at $2.45 \mathrm{GHz}$ in HFSS and CST (a)-(b) without four E-shape resonators (c)-(d) with four E-shape resonators. 


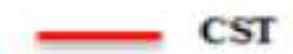

\section{HFSS}

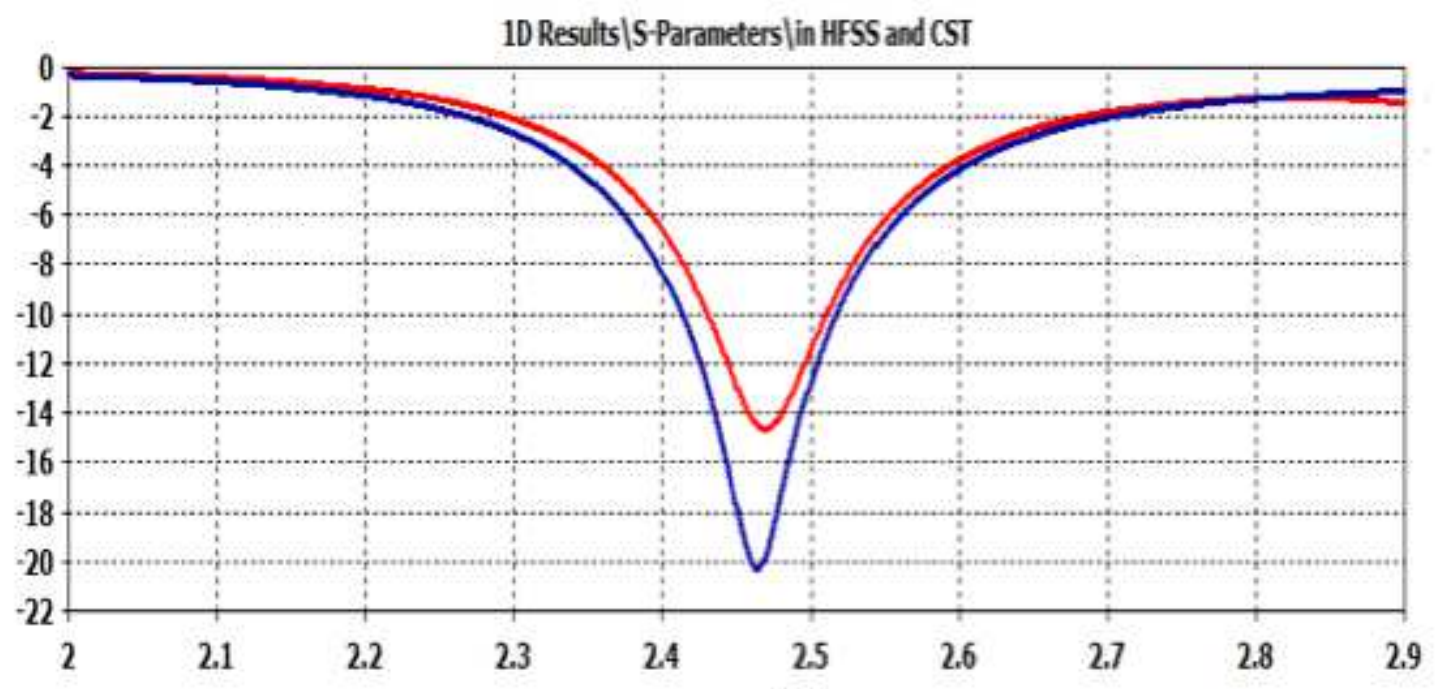

(a)

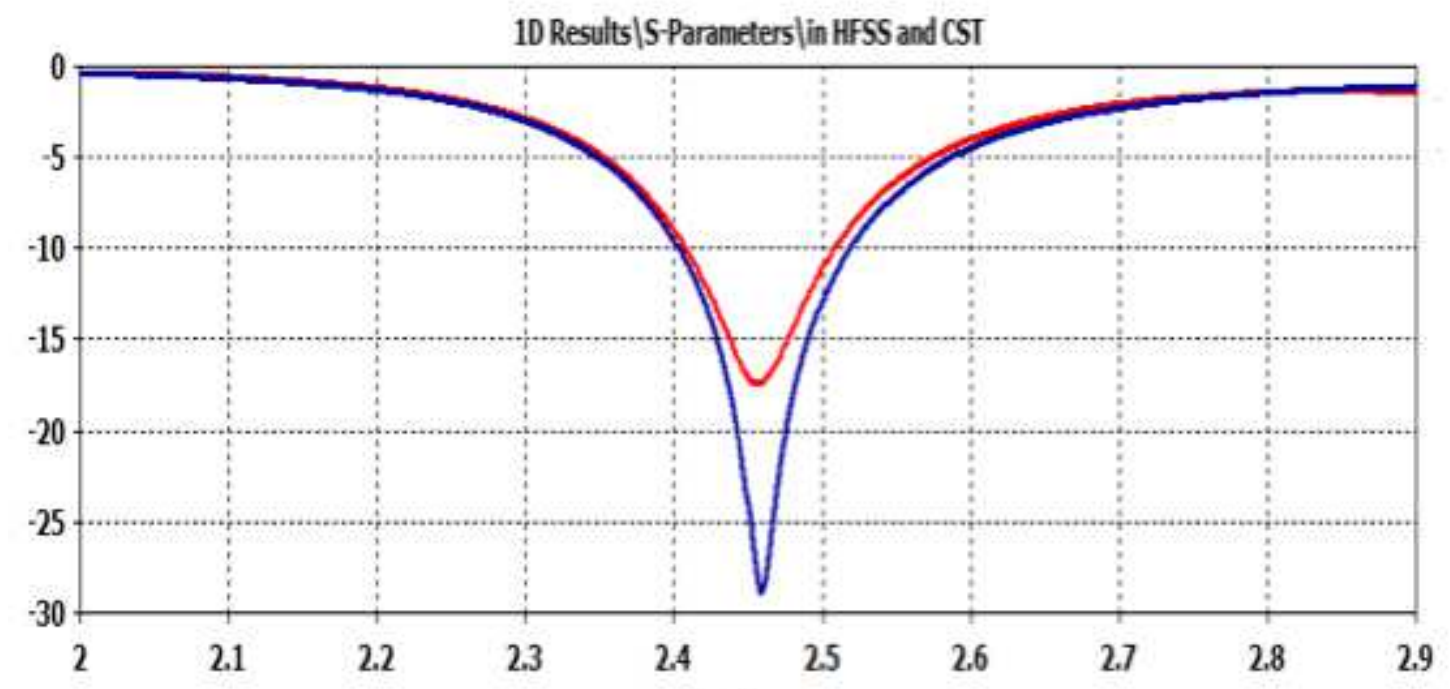

(b)

Figure 10

Variation of S-Parameters (a) one-layer tissue model (b) three layer tissue model. 
Farfield gain pattern 1D Results $\backslash$ Farfield gain pattern

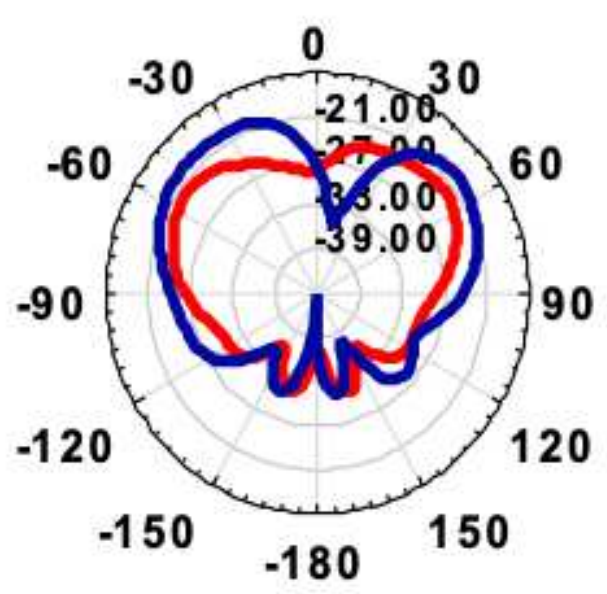

(a)
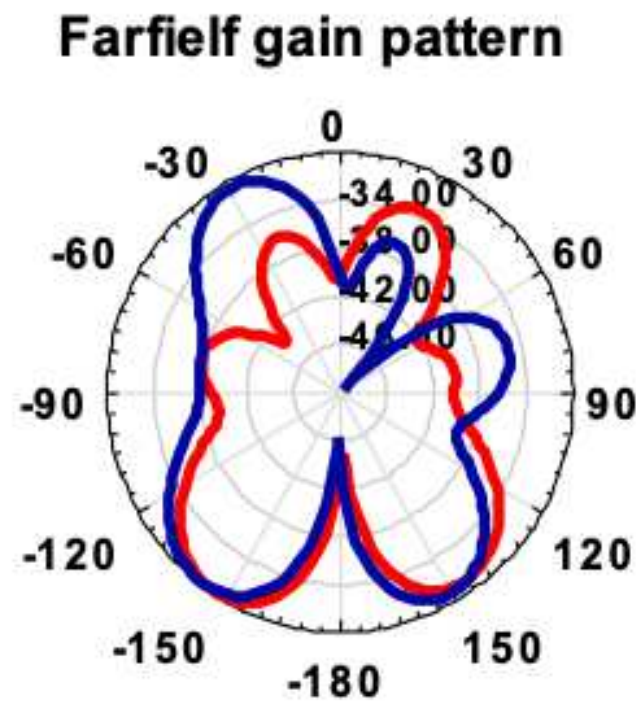

(c)

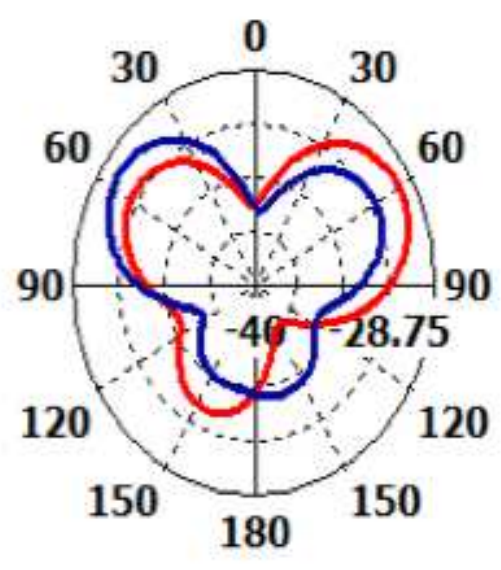

(b)

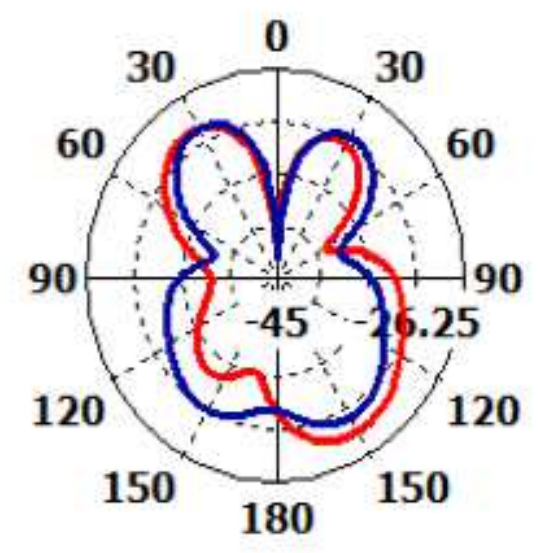

(d)

HFSS: (a)-(c)

CST: (b)-(d)

Figure 11

Farfields radiation gain pattern at $2.45 \mathrm{GHz}$ : in One layer tissue model (a)-(b) and in three layer tissue model (c)-(d). 


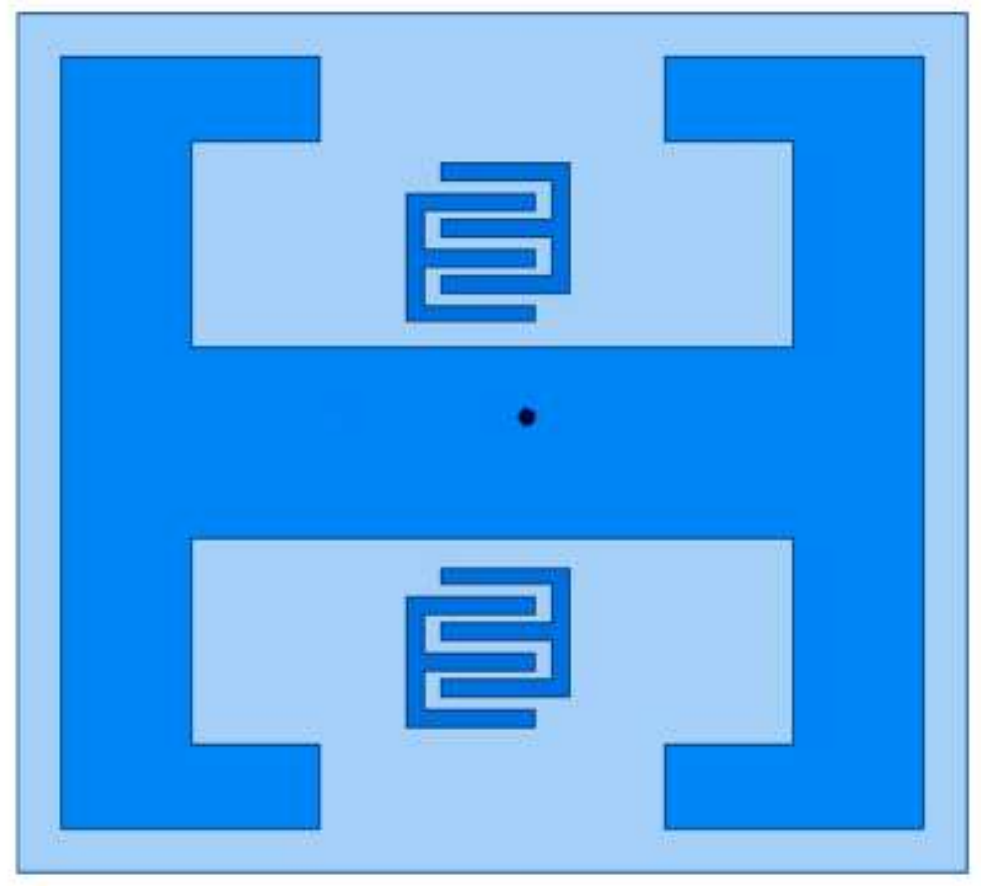

(a)

\section{Unit cell:}

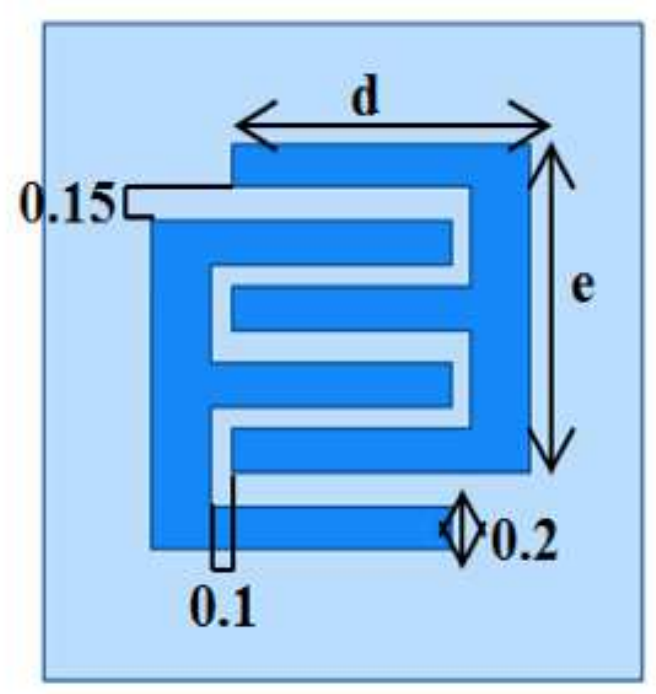

(b)

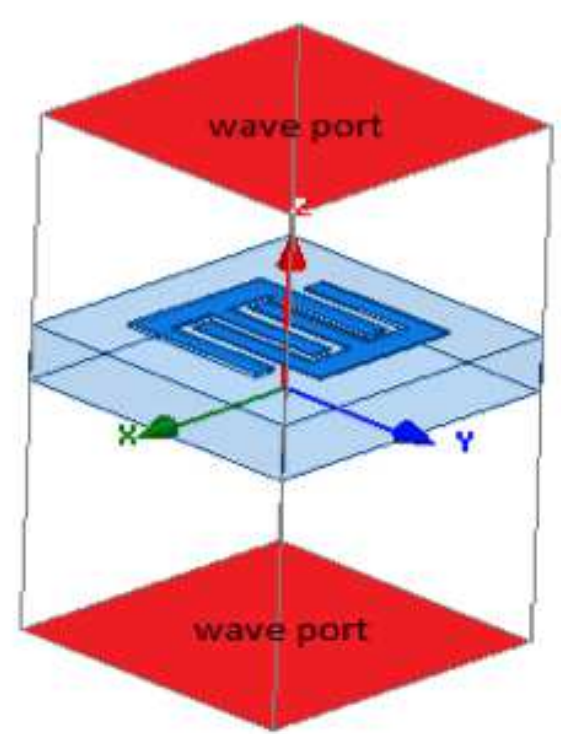

(c)

Figure 12

The proposed antenna (a) Front view (b) The cross sectional view of MTM E- interdigital resonators, (c) Unit cell. 


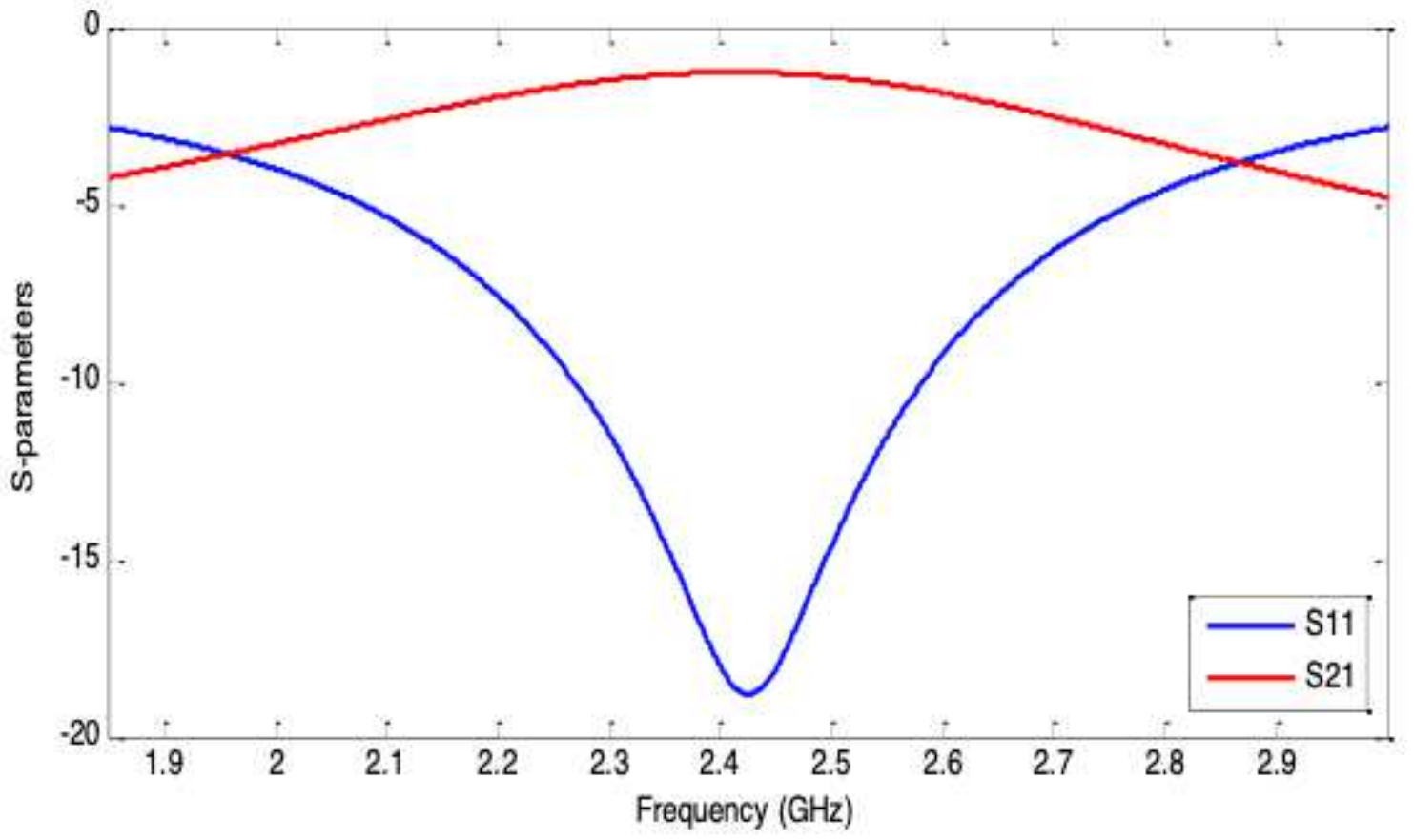

Figure 13

The S-parameters (S11, S21) 


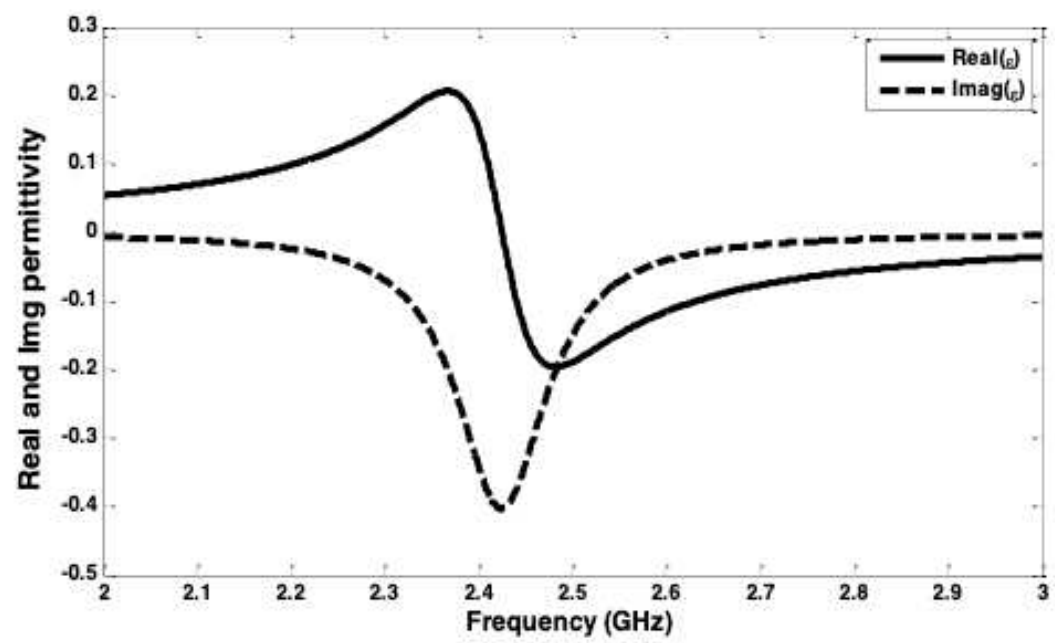

(a)

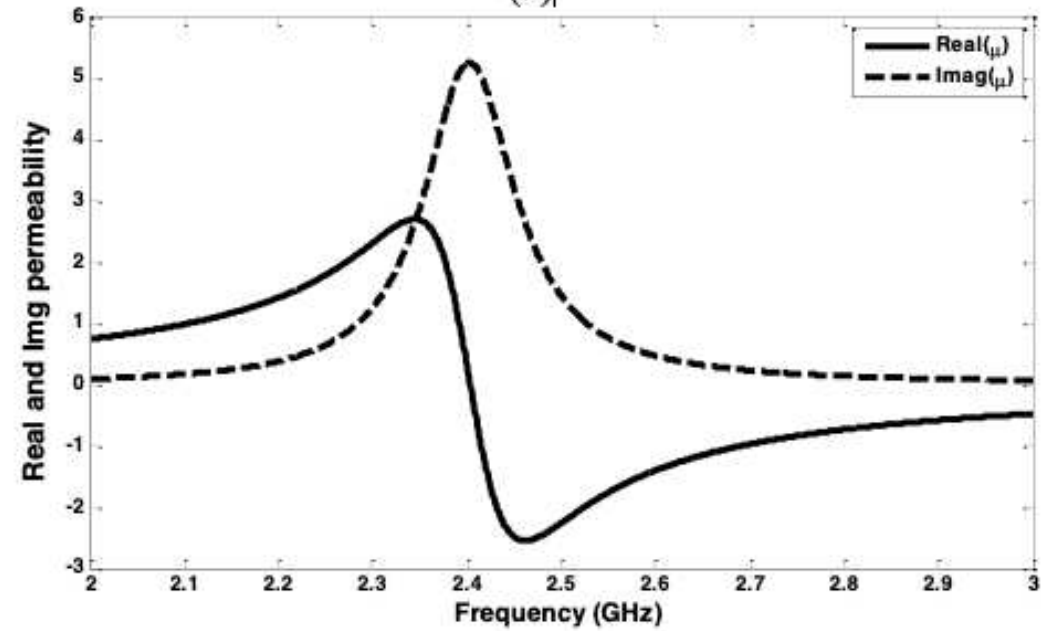

(b)

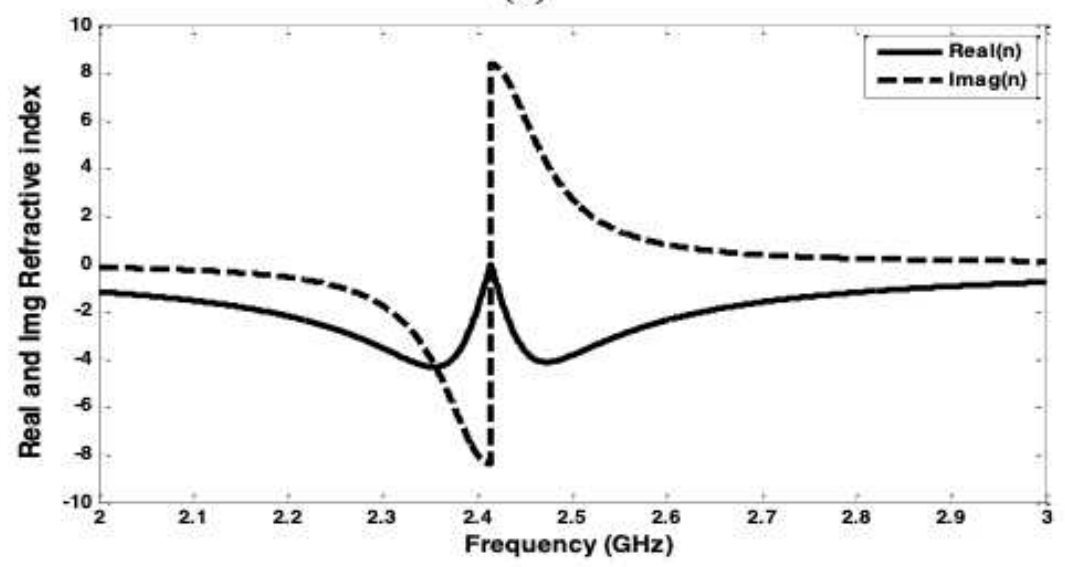

(c)

Figure 14

The real and imaginary part of (a) Permittivity (b) Permeability (c) Refractive index. 


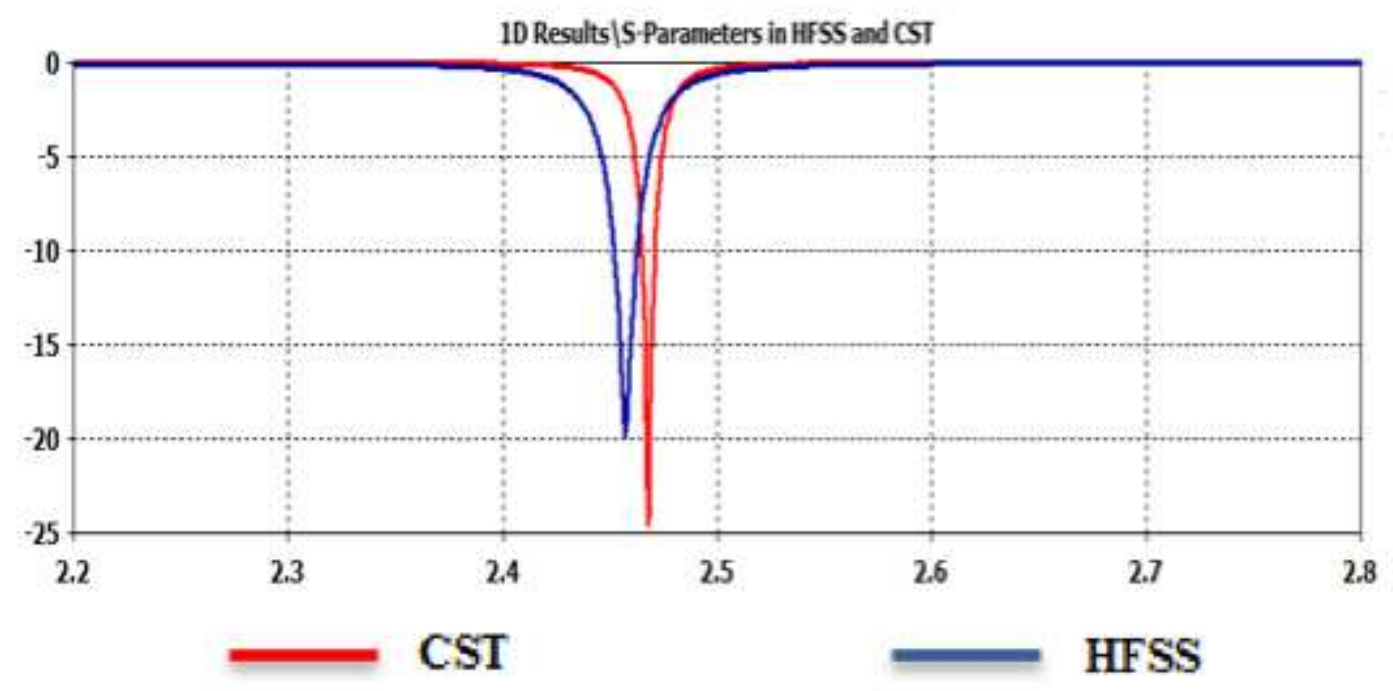

Figure 15

Variation of S-Parameters with Frequency with MTM E-interdigital in free space.

E plane $\quad H$ plane

\section{Farfield gain pattern $\quad$ 1D Results $\backslash$ Farfield gain pattern}

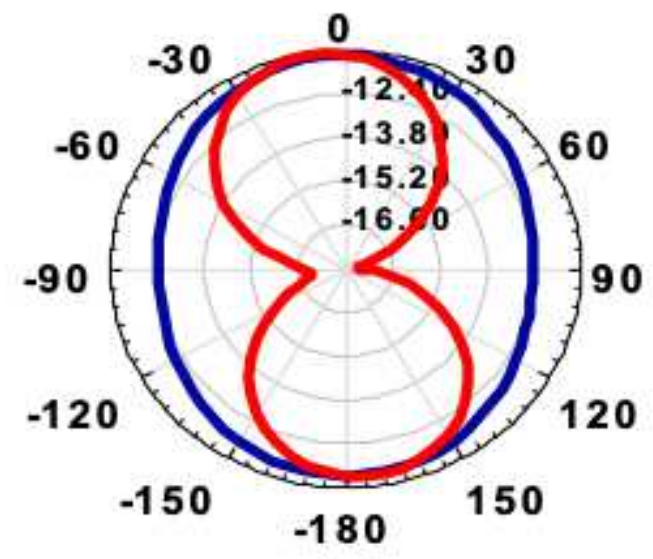

(a)

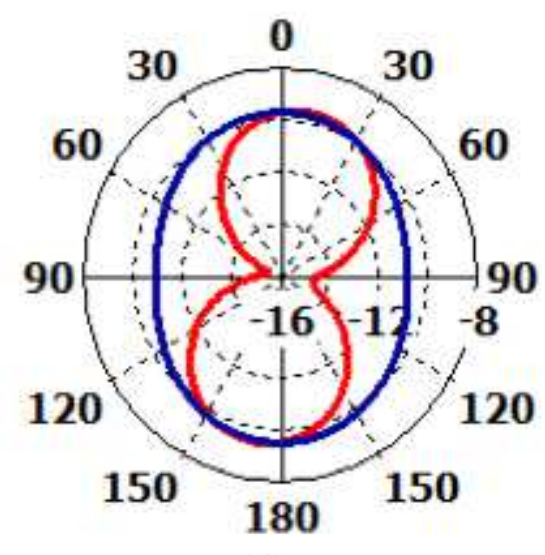

(b)

Figure 16

Farfields radiation gain pattern in free space at $2.45 \mathrm{GHz}$ in (a) HFSS (b) CST. 


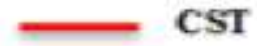

HESS

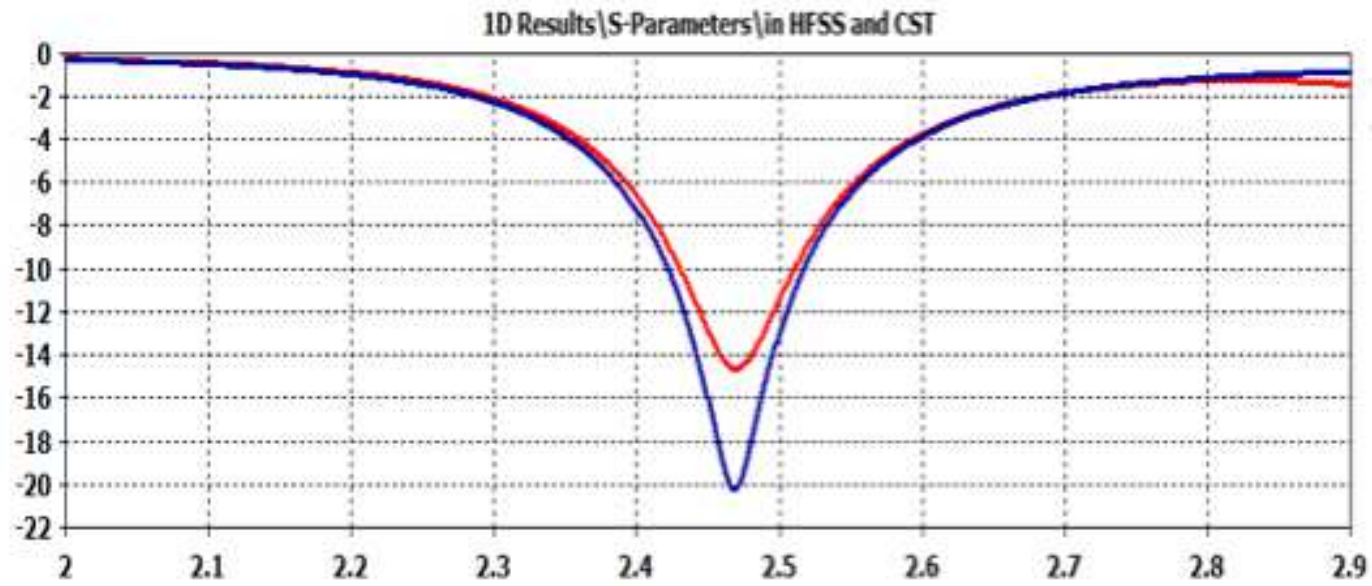

(a)

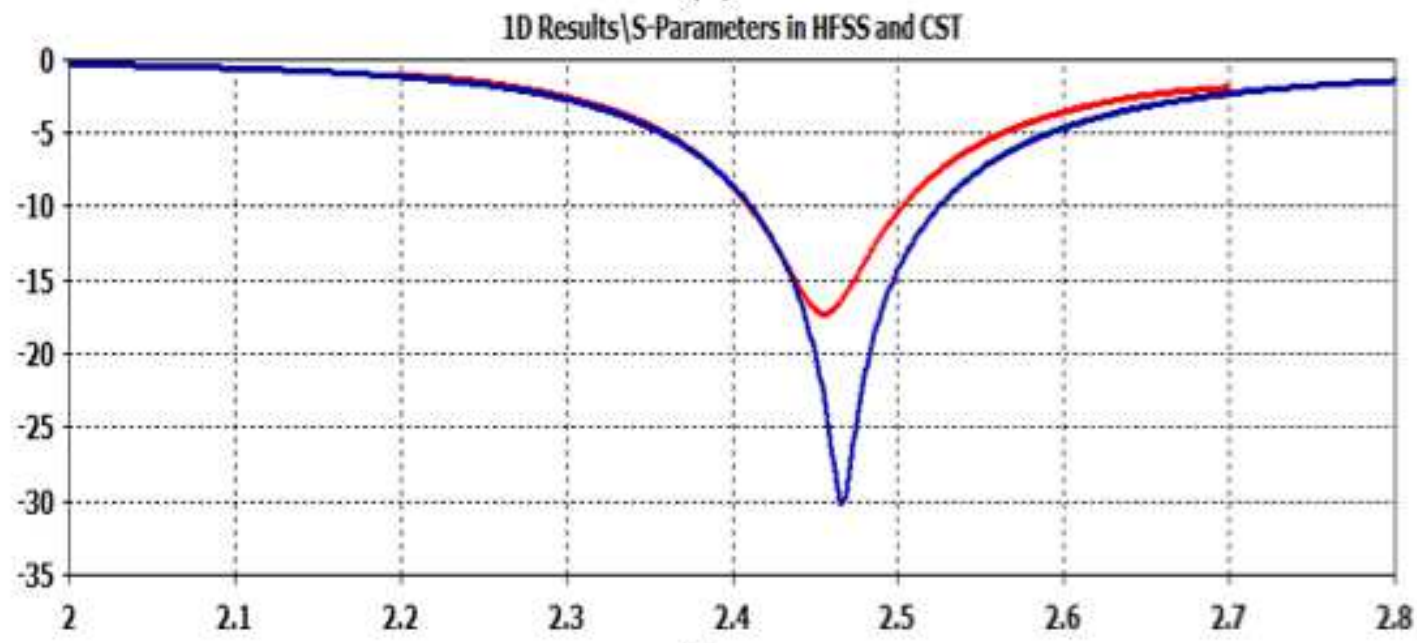

(b)

\section{Figure 17}

Variation of S-Parameters (a) One-layer tissue model (b) three-layer tissue model. 
E plane $\longrightarrow$ H plane

Farfield gain pattern $\quad$ 1D Results $\backslash$ Farfield gain pattern

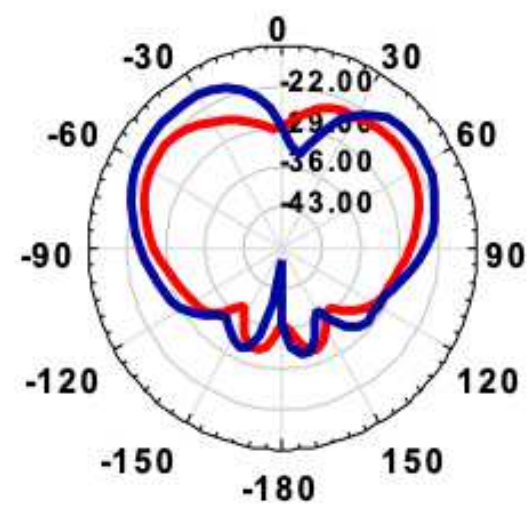

(a)

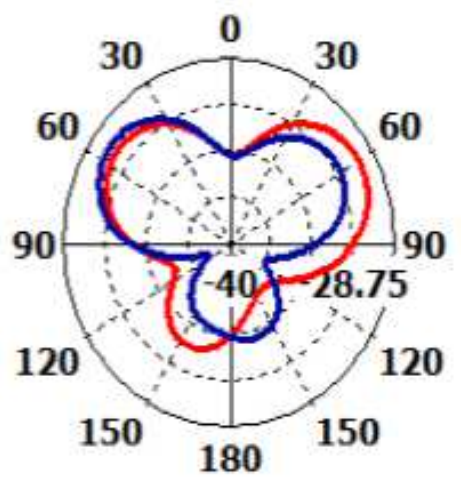

(b)

\section{Farfield gain pattern 1D Results\Farfield gain pattern}

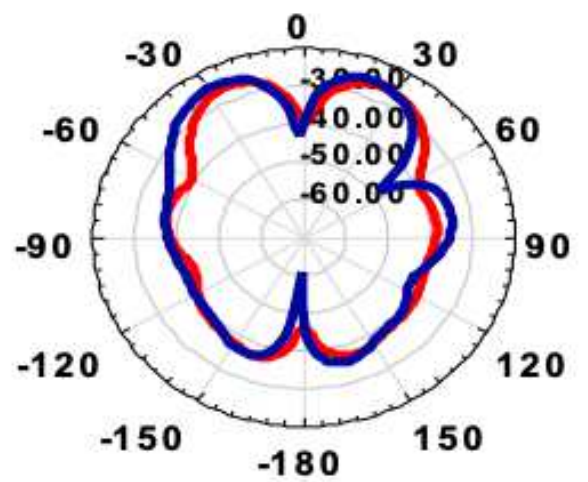

(c)

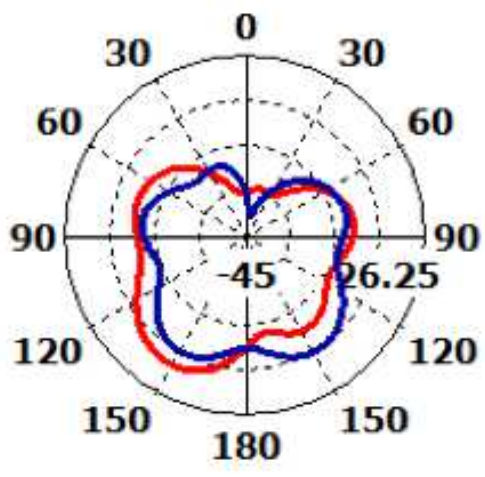

(d)

\section{HFSS: (a)-(c)}

CST: (b)-(d)

\section{Figure 18}

Farfields radiation gain pattern at $2.45 \mathrm{GHz}$ in One-layer tissue model (a)-(b) and in three-layer tissue model (c)-(d). 


\section{CST}

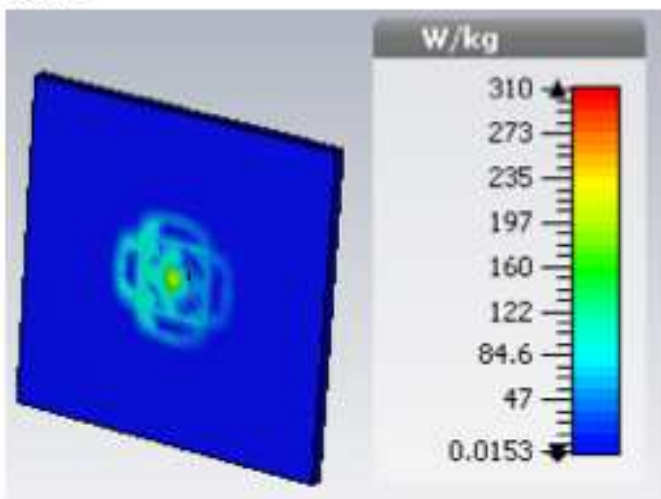

(a)

\section{HFSS}

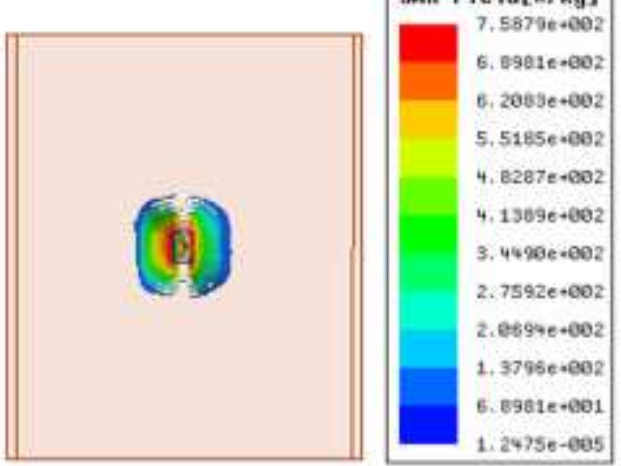

(c)

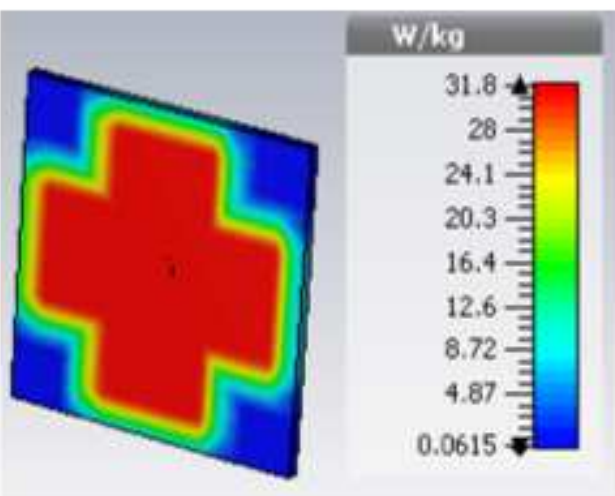

(b)

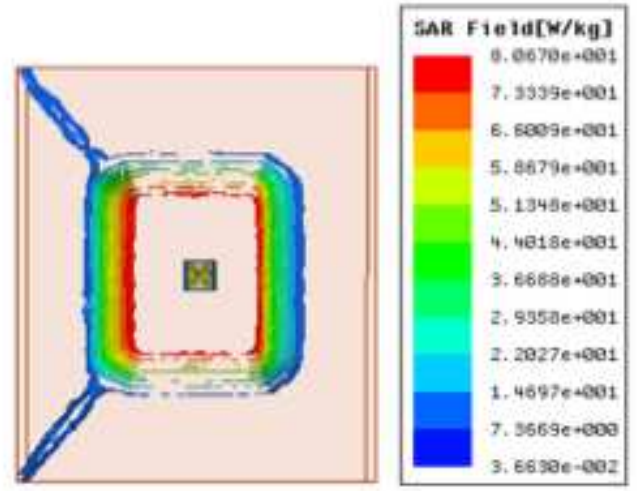

(d)

\section{Figure 19}

SAR distribution of four E-shape resonators in the skin in CST and HFSS (a)-(c)1g (b)-(d) $10 \mathrm{~g}$. 


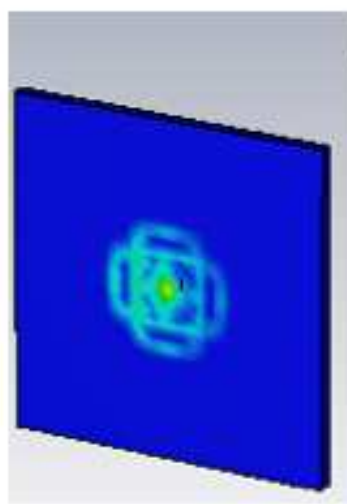

(a)

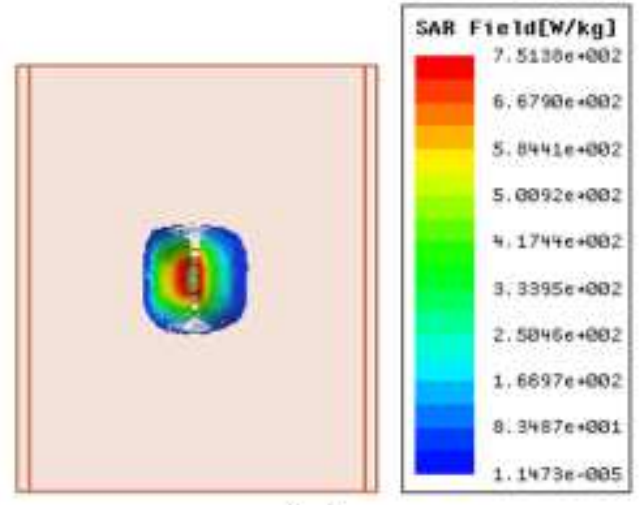

(c)

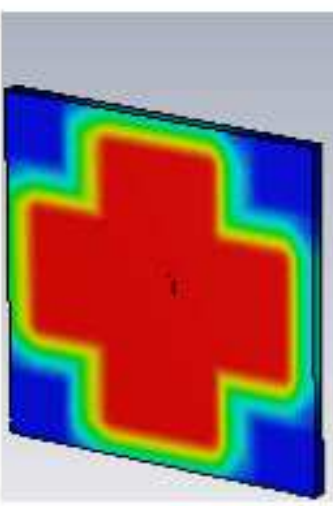

\section{$\mathrm{W} / \mathrm{kg}$}

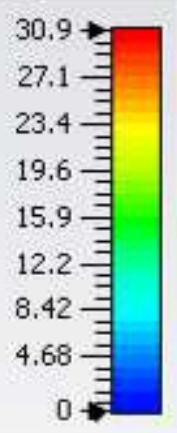

(b)

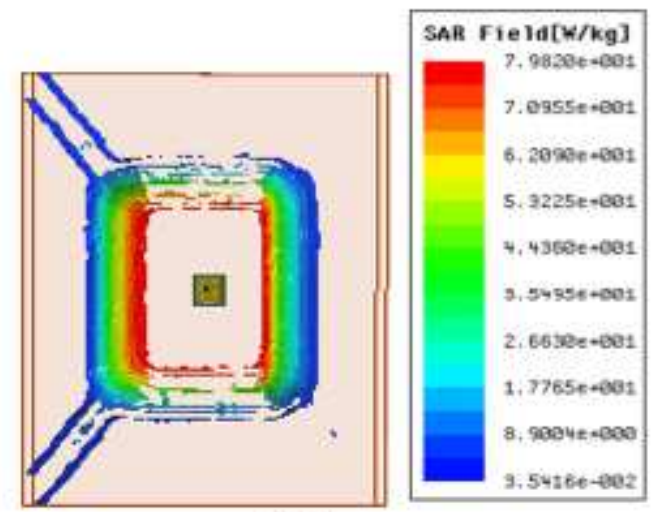

(d)

Figure 20

SAR distribution of E-interdigital resonators in the skin in CST and HFSS (a)-(c)1g (b)-(d) $10 \mathrm{~g}$. 